\title{
The Magnitude and Profile, Distribution Patterns and Associated Factors of AIDS-related Opportunistic Diseases in Adults on Antiretroviral Therapy in Malawi
}

Hemson Hendrix Salema ( $\square$ h.h.salema@warwick.ac.uk)

Division of Health Sciences, University of Warwick Medical School

\section{Research Article}

Keywords: Human Immunodeficiency Virus, Acquired Immunodeficiency syndrome, Antiretroviral therapy, AIDS-related opportunistic diseases, Magnitude, Spectrum

Posted Date: January 14th, 2021

DOl: https://doi.org/10.21203/rs.3.rs-143802/v1

License: (c) (1) This work is licensed under a Creative Commons Attribution 4.0 International License. Read Full License 
The Magnitude and Profile, Distribution Patterns and Associated Factors of AIDSrelated Opportunistic Diseases in Adults on Antiretroviral Therapy in Malawi.

${ }^{1}$ Hemson Hendrix Salema,

[ ${ }^{1}$ Epidemiology \& Biostatistics, Division of Health Sciences, University of Warwick Medical School, Coventry, UK]

Address for correspondence:

Hemson Hendrix Salema (Ph.D. Student).

Division of Health Sciences

Epidemiology \& Biostatistics

Warwick Medical School

University of Warwick

Gibbet Hill Road

Coventry

CV4 7AL, UK

Tel: +44 (0) 7882150743

Skype: hemson.h.salema

Email: h.h.salema@warwick.ac.uk,

Alternate email: $\underline{\text { hsalema02@outlook.com }}$ 


\section{ABSTRACT}

Background: Over one million people in Malawi are HIV infected and many suffer from AIDS-related opportunistic diseases (ODs). However, little is known about the clinical profiles of these ODs and their associated risk factors. We describe the burden and spectrum of ODs in HIV-infected adults on combined antiretroviral therapy (cART) since the countrywide scale-up of free HIV treatment.

Methods: A retrospective chart review was conducted across all three regions in Malawi. Clinical data on prevalent and incident AIDS-related ODs in patients commenced cART from 2004-2015 were abstracted from case notes between March and May 2016.

Results: A total of 9,953 patients were included in the analysis. $60.84 \%$ were females and relatively younger than males with mean age difference of $4.75 \pm 2.9$ years. Overall mean age was $40.72 \pm 12.19$ years. $86.85 \%$ were young and middle-aged adults of productive age-group (15-54 years). $65.08 \%$ were urban residents and $59.55 \%$ were from Southern region. 12,814 AIDS-related opportunistic events were extracted: $56.54 \%$ were prevalent AIDSdefining clinical conditions and the rest were incident AIDS-recurrent cases. $7.65 \%$ of patients had no OD manifestation. Commonly occurring aetiological agents were mycobacterial (36.31\%), bacterial (20.77\%), fungal $(15.77 \%)$ and viral $(15.11 \%)$ pathogens. Overall, the most prevalent ODs were mycobacterium tuberculosis (34.39\%), bacterial pneumonia (11.21\%), nontyphoid Salmonella bacteraemia (9.57\%), HIV-wasting syndrome (8.93\%), candidiasis $(6.81 \%)$, isosporiasis $(5.24 \%)$, pneumocystis pneumonia $(4.02 \%)$ and cryptococcal meningitis $(3.72 \%)$. In the multivariable logistic regression, healthcare facility types, gender, age-group, geographical location, CD4 cell count, viral load levels, treatment initiation eligibility criteria and low socioeconomic status were statistically significantly associated with manifestation of AIDS-related opportunistic diseases.

Conclusion: ODs were highly pervasive among HIV-infected adults in Malawi including treatment-experienced patients which affect largely the productive population. Strategies for effective prevention, early detection and proactive management of AIDS-related opportunistic diseases need to be established and strengthened across all patient groups, in all regions and across all ART health facilities regardless of their levels.

Keywords: Human Immunodeficiency Virus, Acquired Immunodeficiency syndrome, Antiretroviral therapy, AIDS-related opportunistic diseases, Magnitude, Spectrum. 


\section{BACKGROUND}

$2 \overline{\text { The human immunodeficiency virus (HIV) epidemic remains one of the greatest global health }}$ 3 challenges faced by humanity in the $21^{\text {st }}$ century (UNAIDS, 2016). It is the longest 4 epidemic/pandemic ever faced by humanity. 74.9 (58.3-98.1) million people have been 5 infected with HIV since the epidemic started and 37.9 (32.7-44.0) million are currently living 6 with HIV of which, 36.2 million are adults (UNAIDS, 2019a). Furthermore, 32.0 (23.6-43.8)

7 million people have died of AIDS-related illnesses and 770,000 (570,000-1.1 million) of 8 deaths occurred in 2018 (UNAIDS, 2019a). HIV causes progressive depletion of CD4 T 9 lymphocyte cells leading to debilitating, life-threatening ODs (Chaisson \& Moore, 1997; 10 FMOH, 2008; Hogg et al., 1999; Miller et al., 1999; Mitiku et al., 2015; Siberry et al., 2013). 11 Earlier epidemiological studies established that over 90\% of ODs are responsible for AIDSrelated mortalities (Lifson et al., 1988). Due to its pathophysiology, HIV progression is directly

13 linked to ODs which may constitute the initial manifestation of HIV infection indicating 14 significant immunodeficiency (Lifson et al., 1988). Different factors including exposure to potential pathogens and their virulence, degree of host immunity and antimicrobial prophylaxis usage, are (known to be) responsible for the development of ODs among people living with HIV (PLHIV) (Chaisson \& Moore, 1997).

AIDS-related opportunistic diseases are directly linked to many negative personal effects. These include reducing patient's quality of life, speed-up HIV progression rate, affect patient's response to ART specifically in HIV/TB co-infection, increase stigma, limit patient's ability to personal development and social functions, and are associated with high medical costs (Chaisson \& Moore, 1997; Staine, 2007). Opportunistic conditions therefore are a precursor to poverty at both family and national level and remain a major cause of morbidity/mortality among PLHIV even after initiating treatment (Simmons et al., 2013; Weldegebreal et al., 
2018). Following ART initiation, some patients fail to reach the required ART threshold or a sustained response to antiretroviral agents leading to death (Benson et al., 2004; FMOH, 2008). Factors such as late HIV diagnosis, initial acquisition of drug-resistant HIV strain, suboptimal ART use and/or poor adherence, drug toxicities and interactions, poverty, poor nutrition and high exposure to infections have been attributed to mortality post-ART initiation (Bonnet et al., 2005; Brooks et al., 2009; Corey et al., 2007; Manosuthi et al., 2007; Moges \& Kassa, 2014; Paton et al., 2006; Sun et al., 2006).

Although the natural pathophysiological pattern of HIV tends to be similar in most patients, the patterns of ODs that largely define the symptomatic and clinical manifestation of HIV infection tend to differ across different global regions (Colebunders \& Latif, 1991; Holmes et al., 2003; Selik et al., 1987). There is therefore existing disparity in magnitude and profile of AIDS-related opportunistic conditions between high-income and low-income countries and within the low-middle income countries (Iroezindu, 2016; UNAIDS, 2017a; WHO, 2007). Thus; while HIV patients in developed nations rarely suffer from serious ODs, these remain major morbidity and mortality causes within resource-limited nations (Benson et al., 2004; Corey et al., 2007; Croxford et al., 2017; Ghys et al., 2007; Hogg et al., 1999; Reniers et al., 2014). As such, the need for HIV programmes to determine the magnitudes and profile of ODs affecting PLHIV in any nation is crucially imperative. This will assist to deliver impactful interventions and effectively manage resources.

47 Since the national scale-up of free antiretroviral drugs (ARVs) to eligible HIV-infected persons in 2004, Malawi has accomplished much in terms of HIV service expansion. Antiretroviral 49 therapy (ART) clinics grew from 9 (in 2003) to 23, 60, 130 and 716 by December 2004, 2005, 2006 and 2015 respectively) (Jahn et al., 2016; NAC, 2003; WHO, 2005). However, despite 
the WHO estimates of Malawi's antiretroviral therapy need of approximately 130,000 and 169,000 HIV-infected eligible patients in 2003 to 2005; only 4,000, 13,000 and 28,110 HIVpositive patients received ART in 2003, 2004 \& 2005 respectively (Jahn et al., 2016; NAC, 2003; WHO, 2005). By December 2015, 68\% of approximately 1.1 million Malawi’s HIV population was receiving ART (Malawi-MoH, 2017; MOH, 2017; WHO \& UNAIDS, 2016). Moreover, the 20016/2017 indicators progressively shown Malawi being on course with the WHO's 90-90-90 targets (Chirwa et al., 2018; Malawi-MoH, 2017; UNAIDS, 2017b). Furthermore, evidence indicates that HIV prevalence among the 15-49-year-olds has been declining steadily from $16.4 \%$ in 1999 to $11.8 \%$ in 2004 and $10.8 \%$ in 2010 and presently; 9.2\% in 2018 (UNAIDS, 2019b; UNAIDS \& MOH, 2015). The country's rapid and successful ARV scale-up from 2004-2015 has markedly changed HIV epidemic trajectory and reduced its incidence, mortality, and morbidity. By December 2015, 1 in $20 \mathrm{HIV}$-infected adults were on antiretroviral treatment, thereby averting approximately 275,000 deaths and gaining 1.4 million life-years of mostly young adults in their peak productive life (UNAIDS \& MOH, 2015). By Dec $2018,90 \%$ of PLHIV knew their status, of which $87 \%$ were on treatment and $89 \%$ were virally suppressed (AVERT, 2019; UNAIDS, 2019b).

67

However, despite tremendous gains, the incidence and prevalence of AIDS-related opportunistic diseases in Malawi remains arguably high in both ART-exposed and ART-naïve patients (Geubbels \& Bowie, 2006; Kalua et al., 2018). However, nationwide evidence of their magnitudes and profiles, and distribution patterns and aetiological factors, are lacking. Few studies have concentrated on data from individual ART centres with relatively small sample sizes, and mainly targeting specific clinical conditions, thereby, limiting their generalisability (Caruz et al., 1998; Geubbels \& Bowie, 2006; Jahn et al., 2016; Kanyerere et al., 2016; 
study intends to address this deficit and provide national representative data on AIDS-defining and recurrent opportunistic conditions (ADROC) among HIV-infected adults on combined antiretroviral therapy (cART) in Malawi. Besides, the study aims to compare ADROC trends during early and late ART periods.

\section{MATERIALS AND METHODS}

\section{Study settings}

This study was conducted in 8 ART facilities randomly selected across all three regions of Malawi. These are specialised clinics dedicated to HIV care, majority of which are within existing health facility establishments. Data collection centres included one primary level (health centre) facility, 4 secondary level (district hospitals) and 3 tertiary level (central hospitals) facilities. Despite differences in facility's levels, in general, routine activities at each facility included assessment of patients prior to admission into care. HIV-infected persons are referred from either satellite HIV testing centres or screened from the facility’s general outpatient department, accident and emergency or in-patient wards and from antenatal clinics under Option B+/PMTCT criteria. At the ART centre, patients are re-tested of HIV (confirmatory testing) before admitted into HIV care. Those with a positive confirmatory HIV test are screened for existence of comorbid conditions (ODs) and ART eligibility. Traditionary, screening involved classifying patients into WHO clinical stages I-IV of HIV, but later included baseline CD4 cell count (and viral load levels, where required) measurements. WHO stage III \& IV and low CD4 count below recommended thresholds have traditionary been treatment-initiation criteria and such patients were commenced on standardised antiretroviral therapy. If patient's condition does not satisfy ART-initiation (based on guidelines in use), they were closely monitored with 3-month scheduled clinical reviews or whenever the person feels 
unwell, except mothers under Option B+/PMTCT criteria since July 2011. Since 2016, the

102 guidelines treatment-eligibility have however changed test-and-treat whereby, every HIV-

103 positive person is expected to commence treatment regardless of stage, CD4 count or

104 pregnancy/breastfeeding. This study recruited only patients who were eligible for and

105 commenced on standard ART regimen, regardless of present outcome. HIV patients' medical

106 records called ART Master cards were used as sampling frames.

107

\section{Study Design and Study Participants}

109 A retrospective chart review (RCR) study was conducted between March and May 2016.

110 Subjects were HIV-infected adults aged 15+ years who commenced antiretroviral therapy

111 under the standardised treatment protocols between Jan 2004 and Dec 2015. Participants were

112 randomly selected from the 8 participating health facilities. All AIDS-defining and recurrent

113 opportunistic conditions (diseases) were considered as study outcomes.

115 Study time was structured into two time-periods corresponding to major milestones in HIV

116 management in relation to treatment initiation clinical eligibility criteria. The first period was

117 designated "early-ART 20004-2011". This refers to period between 2004-2011 when cART

118 was initiated to only severely ill patients with either clinical stage III or IV of HIV disease or,

119 CD4 cell count $<200$ cells/ $\mu \mathrm{L}$. This was based on $2003 \& 2006$ WHO recommended guidelines

120 for ART initiation (Jahn et al., 2016; MOH, 2011; WHO, 2006; WHO, 2010b; WHO, 2010c;

121 WHO, 2013). The second period was designated "late-ART (2011-2015)" and refers to period

122 between 2011-2015 when ART access was expanded to include patients with CD4 count $\leq 350$

123 cells/ $\mu$ L regardless of WHO clinical stage (MOH, 2011; WHO, 2010b; WHO, 2010c; WHO,

124 2013). 


\title{
125 Sample Size and Sampling Procedure
}

126 The sample size was determined using the following simple formula and assumptions

127 recommended and endorsed for prevalence studies (Charan \& Biswas, 2013; Daniel, 1999;

128 Daniel \& Cross, 2013; Gorstein et al., 2007; Hajian-Tilaki, 2011; Naing et al., 2006):

$$
n=Z \frac{\alpha^{2}}{2}\left(\frac{P(1-P)}{d^{2}}\right) x D
$$

\begin{abstract}
Where: $n=$ is the sample size; $\mathrm{P}=$ expected prevalence of ODs in Malawi @ 10.6\% based on 2010 MDHS; $\mathrm{d}=$ margin of error between sample and population sizes ( $\mathrm{n}$ vs N) (0.006); $z \frac{\alpha^{2}}{2}=$ statistical critical value at $95 \%$ confidence interval (1.96); D = design effect for a cluster sampling of sampling frames (DHOs, health facilities \& ART Master cards) estimated @ 2.0.
\end{abstract}

130

131 The estimated sample size; $(n=8,654)$, was adjusted by $15 \%$ allowance to compensate for poor medical records documentation observed during the pilot study, resulting in final sample size

133 of $(n=9,953)$. A three-stage systematic sampling method was used to select the required health

134 facilities and medical records. To select health facilities, the 2015 Ministry of Health HIV Unit 135 report was used (Jahn et al., 2016; NAC/MOH \& UNAIDS, 2015). The report stated that a 136 total of 716 ART facilities were operational in Malawi (ibid.). It was further established that 4 137 of these ART centres were in central hospitals, 44 in district and CHAM hospitals, 35 in rural 138 hospitals and 328 in health centres while the rest $(\mathrm{N}=305)$ were dispensaries and private 139 hospitals. For this study, only static, public sector, and not-for-profit health facilities $(\mathrm{N}=411)$, 140 across all administrative District Health Offices (DHOs) were considered as potential data 141 collection centres. I determined to sample from 8 ART centres from 5 DHOs and proportionally 142 divide the sample size according to per-facility patient load. Participating DHOs and ART 143 facilities were randomly selected using probability sampling techniques; stratified random 
sampling and the systematic random sampling from the formula.... $K=N / n$ (Trochim, 2000;

145 Trochim, 2007)

- $\mathrm{N}$ is the number of cases (DHOs or ART Centres) in the sampling frame.

- $\mathrm{n}$ is the number of cases (DHOs or ART Centres) in the sample.

The procedure involved stratifying participating sites and subjects into DHOs, ART facilities and patients' medical records (the Master cards). The randomly selected DHOs were Mzimba, and 1 health centre-based ART facilities were randomly selected as data collection centres.

At each ART centre, exclusion criteria were applied to the main data frame $\left[\left(N_{1}\right)\right]$, to form a stratum of eligible patients $\left[N_{2}\right]$, the final data frame. Likewise, the sampling procedure was replicated to randomly select medical records from $N_{2}$. Then, anonymised patients' serial numbers $\left[\right.$ from $\left.\left(N_{2}\right)\right]$ were randomly listed from which... $n_{1}, n_{2}, n_{3}, n_{4}, n_{5}, \ldots \ldots . . n_{x}$ serial numbers were randomly picked.

\section{Data Collection Tools and Procedures}

163 Data were collected using an electronic ADROC research tool developed a priori. The data

164 collection tool reflected information on the ART master card - a patient medical record used 165 from point of entry to ART services. The tool was specifically designed to capture data on both 166 prevalent and incident AIDS-associated clinical conditions and their associated factors. The 167 tool was piloted at 2 centres; a central hospital and district hospital based centres following which, minor amendments were made. At every centre I recruited and trained a sizable research 
team with unrestricted access to the local data. The teams were trained on the contents of the tool and how to use it to collect relevant data.

\section{Data Management and Quality Assurance}

173 Strict adherence to data collection standards was encouraged and closely monitored at each centre by close supervision of data extraction exercise. Data were checked for completeness and consistency and randomly double-entered to ensure high data quality from point of entry.

\section{Data Analysis}

178 Descriptive statistics were used to analyse socio-demographic and clinical parameters. For 179 continuous variables, mean with standard deviation $( \pm \mathrm{SD})$ and median with interquartile range 180 (IQR) were reported. Findings between patient with and patients without manifestation of 181 aetiological factors or the opportunistic disease were compared. The two-sample $t$-test (and the one-way analysis of variance, where appropriate) were used to determine and compare statistically significant differences between means of independent variables. For categorical variables, frequency or proportion values were expressed as absolute numbers or percentages and differences compared between the two patient groups for statistical significance using Chisquare test. Bivariable logistic regression was used to determine crude associations between independent variables and OD manifestations. Odds ratios with $95 \%$ confidence intervals (OR 95\% CI) were used as a measure of association. Multivariable analysis was used to determine independent effects of selected variables on OD manifestation while controlling for the effects

190 of other variables in a complete case analysis. Independent factors with a $p \leq 0.25$ from the crude 191 analysis were entered into final model with associations reported as adjusted odds ratio (aOR, $19295 \%$ CI). Significance level was set by a two-tailed alpha $(\alpha)$ of 0.05 . The multicollinearity 
193 tolerance test, Hosmer-Lemeshow test and the linktest regression diagnostic tests were used to

194 judge goodness-of-fit of final model. Data analysis was conducted using Stata software special 195 edition for windows v15.1.

196

197

RESULTS

\section{Socio-Demographic Characteristics of Study Participants}

200 The socio-demographic characteristics of participants are presented in Table 1. A total of 9,953 medical records of HIV-infected adults were recruited. These patients were once initiated on ART between Jan 2004 and Dec 2015 following standardised national treatment protocols. Medical records retrieval rate was $100 \%$ of the planned records. The overall mean $( \pm \mathrm{SD})$ age was $40.72 \pm 12.19$ years. Most subjects were females $(60.84 \%)$, which were also relatively younger than males; mean age: 38.86 vs 43.61 years respectively, and significant mean age difference of 4.75 years $(p<0.0001) .83 .25 \%$, were young, middle-aged adults of productive group aged 20-54 years old. Majority of patients $(65.08 \%)$ were urban residents and from Southern region $(59.55 \%)$ while Northern and Central regions accounted for $15.92 \%$ and $24.53 \%$ respectively. $78.76 \%$ were married and $13.87 \%$ were either divorced or widowed while

210 only $7.36 \%$ were ever-single. The preponderance $(67.68 \%)$ were recruited from tertiary-level

211 health facilities. The proportions of patients with primary and secondary education attainment

212 were indifferent; $33.65 \%$ and $32.75 \%$ respectively, while $7.16 \%$ had no formal education. More 213 than half $(55.32 \%)$, were permanently employed while the rest were self-employed and $21433.62 \%$ were engaged in office-based work. 


\begin{tabular}{|c|c|c|c|}
\hline Characteristic & Number (\%) & Characteristic & Number (\%) \\
\hline Care type & & Marital status & \\
\hline Primary care & $735(7.38)$ & Previously married & $1,380(13.87)$ \\
\hline Secondary care & $2,482(24.94)$ & Married (partnership) & $7,837(78.74)$ \\
\hline Tertiary care & $6,736(67.68)$ & Single (never married) & $733(7.36)$ \\
\hline Total & $9953(100.00)$ & Total & $9953(100.00)$ \\
\hline Gender & & Education levels & \\
\hline Female & $6,055(60.84)$ & No education & $713(7.16)$ \\
\hline Male & $3,898(39.16)$ & Primary & $3,349(33.65)$ \\
\hline \multirow[t]{2}{*}{ Total } & $9953(100.00)$ & Secondary & $3,260(32.75)$ \\
\hline & & Higher & $2,631(26.43)$ \\
\hline Age-range (years) & & Total & $9953(100.00)$ \\
\hline 15-19 (Adolescents) & $358(3.60)$ & & \\
\hline 20-39 (Young adults) & $4,501(45.22)$ & Employment status & \\
\hline 40-54 (Mid-Aged Adults) & $3,785(38.03)$ & Employed & $5,506(55.32)$ \\
\hline 55+ (Older Adults) & $1,306(13.12)$ & Self-employed & $4,447(44.68)$ \\
\hline Total & $9953(100.00)$ & Total & $9953(100.00)$ \\
\hline Residential area & & Occupation classification & \\
\hline Rural & $2,047(20.57)$ & Manual jobs & $1,658(16.66)$ \\
\hline semi-urban & $1,427(14.34)$ & Others job types & $4,949(49.72)$ \\
\hline Urban & $6,477(65.08)$ & White collar jobs & $3,346(33.62)$ \\
\hline Total & $9953(100.00)$ & Total & $9953(100.00)$ \\
\hline Regional area & & ART-initiation criteria & \\
\hline Central Region & $2,441(24.53)$ & $\mathrm{CD} 4+$ count & $2,475(24.87)$ \\
\hline Northern Region & $1,585(15.92)$ & PMTCT & $261(2.62)$ \\
\hline Southern Region & $5,927(59.55)$ & WHO III & $4,781(48.04)$ \\
\hline \multirow[t]{2}{*}{ Total } & $9953(100.00)$ & WHO IV & $2,436(24.48)$ \\
\hline & & Total & $9953(100.00)$ \\
\hline \multicolumn{4}{|l|}{ Guardian escort } \\
\hline None (no guardian) & $1,471(14.78)$ & & \\
\hline Yes (with guardian) & $8,481(85.21)$ & & \\
\hline Total & $9953(100.00)$ & & \\
\hline
\end{tabular}

222 Baseline Clinical Characteristics of Study Participants

223 The clinical characteristics of the study participants are presented in Table 2. All enrolled 224 patients were once initiated on ART following the national standardised treatment protocols. 72.52\% commenced treatment with advanced HIV disease: WHO clinical stage III (48.04\%) and stage IV (24.48\%). Moreover, $27.49 \%$ were asymptomatic when commenced treatment.

227 Thus, these had either low CD4 cell count below recommended threshold (24.87\%) or were under the Option-B+/PMTCT criteria (breastfeeding or pregnant) (2.62\%). 
230 Overall, the mean \pm SD clinical latency was $527.11 \pm 324.93$ days and was somewhat shorter in

231 females; mean difference: 28.49 days but lacked statistical significance $(p=0.0926)$.

232

233 The mean HIV duration was 2,331.41 1 1,387.99 days while mean ART duration was

$2341,805.15 \pm 1,135.99$ days. Although all patients commenced treatment following standardised

235 regimes protocols; $67.10 \%$ were commenced with Efavirenz-based regimen, 28.53\% with

236 Nevirapine-based regimens while a small proportion (4.37\%), were started on treatment using

237 non-standard ART regimens. Of all participants, 95.41\% were continued on first-line ART

238 regimens while $3.29 \%(\mathrm{~N}=327)$ had been switched onto second-line regimen; the boosted-

239 Ritonavir formulations. This means that these patients had first-line antiretroviral treatment

240 failure. Only $1.31 \%(\mathrm{~N}=130)$ were receiving NS formulations as maintenance regimens.

242 Data on clinical surrogate makers; CD4 count and viral load test results, were extracted at two

243 time-points: as initial (baseline) and as subsequent results (the latter was the most recent

244 available test result). Overall, the mean $( \pm \mathrm{SD})$ initial CD4 count was $145.08 \pm 95.05$ cells/ $\mu \mathrm{L}$.

245 Most patients; 68.69\%, were severely immunosuppressed with initial CD4 count $<250$

246 cells $/ \mu$ L. Following ART treatment, test results in most patients improved considerably to

247 normal healthy adult levels. Such that, the overall mean $( \pm$ SD) subsequent CD4 count was

$248648 \pm 328.66$ cells $/ \mu \mathrm{L}$, and $68.59 \%$ of patients had subsequent CD4 count $>500$ cells $/ \mu \mathrm{L}$.

249 Correspondingly, most patients had severe virologic failure when they commenced treatment.

250 Thus, with overall mean $( \pm \mathrm{SD})$ initial VL levels of $992,768 \pm 949,436$ copies $/ \mathrm{mL}, 78.79 \%$ of 251 patients had $>100,000$ copies/mL initial VL results. Likewise, the overall mean $( \pm$ SD) 252 subsequent VL was relatively lower following cART; 117,083.7 $\pm 381,017$ copies/mL and up 253 to $70.73 \%$ were virally suppressed (VL<1000 copies/mL) of which, $(\mathrm{N}=3,992)$ had 254 undetectable viral load results of $<40$ copies $/ \mathrm{mL}$. 


\begin{tabular}{|c|c|c|c|}
\hline Characteristic & Number $(\%)$ & Characteristic & Number (\%) \\
\hline \multicolumn{2}{|l|}{ ART-initiation criteria } & \multicolumn{2}{|l|}{ Current ART regimen type } \\
\hline CD4+ count & $2,475(24.87)$ & Nevirapine-based & $2,416(24.27)$ \\
\hline РMTCT & $261(2.62)$ & Efavirenz-based & $7,080(71.13)$ \\
\hline WHO III & $4,781(48.04)$ & Boosted-Ritonavir & $327(3.29)$ \\
\hline WHO IV & $2,436(24.48)$ & Non-std. & $130(1.31)$ \\
\hline \multicolumn{2}{|l|}{ CD4 initial results } & \multicolumn{2}{|l|}{ Contraception: Barrier type } \\
\hline $0-250$ cells $/ \mu \mathrm{L}$ & $6,956(69.89)$ & Yes & $7,087(71.20)$ \\
\hline$>=251$ cells $/ \mu \mathrm{L}$ & $2,988(30.02)$ & No & $2,866(28.80)$ \\
\hline \multicolumn{2}{|l|}{ CD4 recent results } & \multicolumn{2}{|l|}{ HIV duration } \\
\hline $100-500$ cells $/ \mu \mathrm{L}$ & $3,125(31.40)$ & $1-2 \mathrm{yrs}$ & $1,342(13.48)$ \\
\hline $501-1,000$ cells $/ \mu \mathrm{L}$ & $5,201(52.26)$ & 3-5 yrs. & $2,610(26.22)$ \\
\hline \multirow[t]{2}{*}{$>=1001+$ cells $/ \mu \mathrm{L}$} & $1,625(16.33)$ & $6-10 \mathrm{yrs}$ & $4,440(44.61)$ \\
\hline & & $>10$ yrs. & $1,561(15.68)$ \\
\hline \multicolumn{4}{|l|}{ Initial VL test results } \\
\hline$<10,000$ copies $/ \mathrm{mL}$ & $798(8.02)$ & ART duration & \\
\hline $10,000-100,000$ copies $/ \mathrm{mL}$ & $1,305(13.11)$ & $1-2$ yrs. & $2,154(21.64)$ \\
\hline \multirow[t]{2}{*}{$>100,000$ copies $/ \mathrm{mL}$} & $7,842(78.79)$ & 3-5 yrs. & $3,243(32.58)$ \\
\hline & & $6-10 \mathrm{yrs}$ & $3,933(39.52)$ \\
\hline Recent VL tests results & & $>10 \mathrm{yrs}$ & $623(6.26)$ \\
\hline$<40$ copies $/ \mathrm{mL}$ & $3,992(40.11)$ & & \\
\hline $40-1,000$ copies $/ \mathrm{mL}$ & $3,048(30.62)$ & Clinical latency range & \\
\hline 1,001-10,000 copies/mL & $1,041(10.46)$ & $1-2$ years & $6,964(69.97)$ \\
\hline $10,001-100,000$ copies $/ \mathrm{mL}$ & $757(7.61)$ & $3-5$ years & $2,259(22.70)$ \\
\hline$>100,000$ copies $/ \mathrm{mL}$ & $1,115(11.20)$ & $>=6$ years & $730(7.33)$ \\
\hline Initial ART regimen type & & Patient-outcome & \\
\hline Nevirapine-based & $2,840(28.53)$ & Treatment adherent & $6,758(67.90)$ \\
\hline Efavirenz-based & $6,678(67.10)$ & Defaulters \& LTFU & $2,018(20.28)$ \\
\hline Non-std. & $435(4.37)$ & Died & $1,177(11.83)$ \\
\hline
\end{tabular}

\section{Treatment Outcomes Status of Study Participants}

260 Figure 1 illustrates last treatment outcome status recorded during most recent patient follow-

261 up visits. $67.90 \%$ of patients were alive and continuing with treatment, $20.28 \%$ were either

262 defaulters, lost to follow-up or stopped treatment whereas $11.83 \%$ had died. 


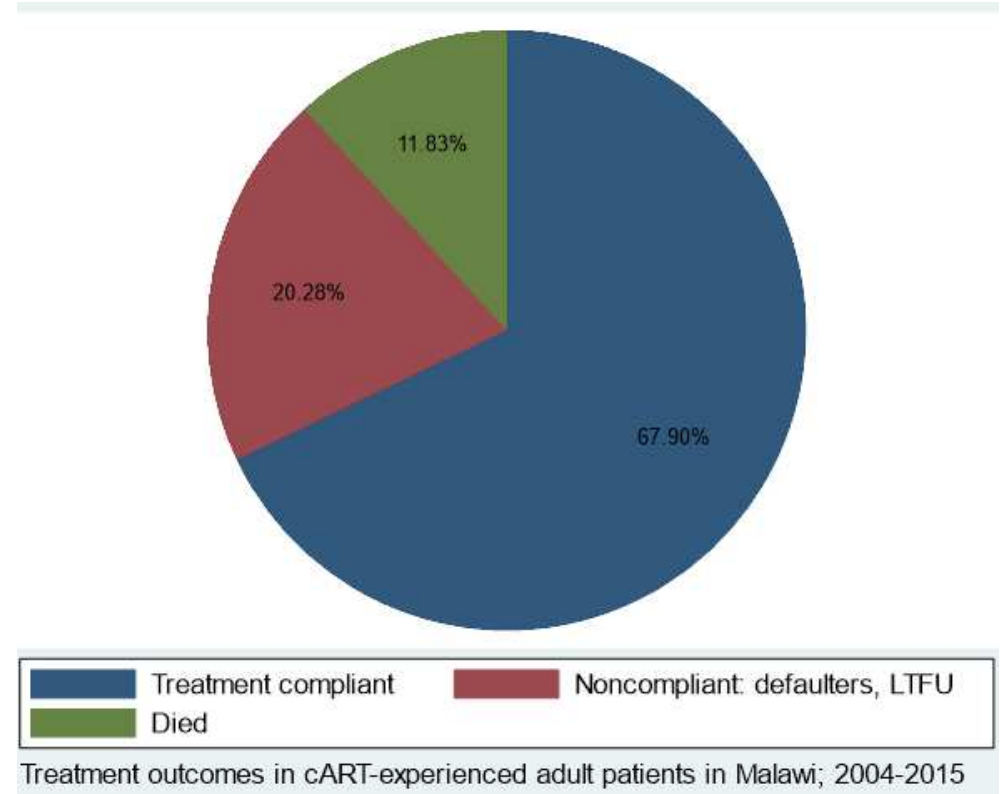

The Magnitude and Profile of AIDS-Associated Opportunistic Conditions

271 From Jan 2004 to Dec 2015, a total of 12,814 episodes of opportunistic disease (AIDS events) were recorded from enrolled patients $(\mathrm{N}=9,953)$. 59.01\% $(\mathrm{N}=7,559)$ cases were prevalent AIDS-defining clinical conditions (ADCCs) that manifested in treatment-naïve patients whereas $40.99 \% \mathrm{~N}=5,255)$ were incident AIDS-recurrent conditions which manifested in treatment-experienced patients. The overall period prevalence of prevalent OD events among treatment-naïve patients during this period was an estimated $72.55 \%$. In contrast, the overall period prevalence of incident OD events among treatment-experienced patients within the same period was an estimated $55.76 \%$ with repeated occurrences in some conditions. Six aetiological agents were responsible for the abstracted opportunistic events and mycobacterial agents were most prevalent $(36.31 \%)$ while neoplastic conditions were the least manifested with only event had occurred, hence, remained asymptomatic. 
Figure 2: Distribution of AIDS Conditions Aetiological Factors; Total and by ART Periods in 285 Malawi; 2004-2015

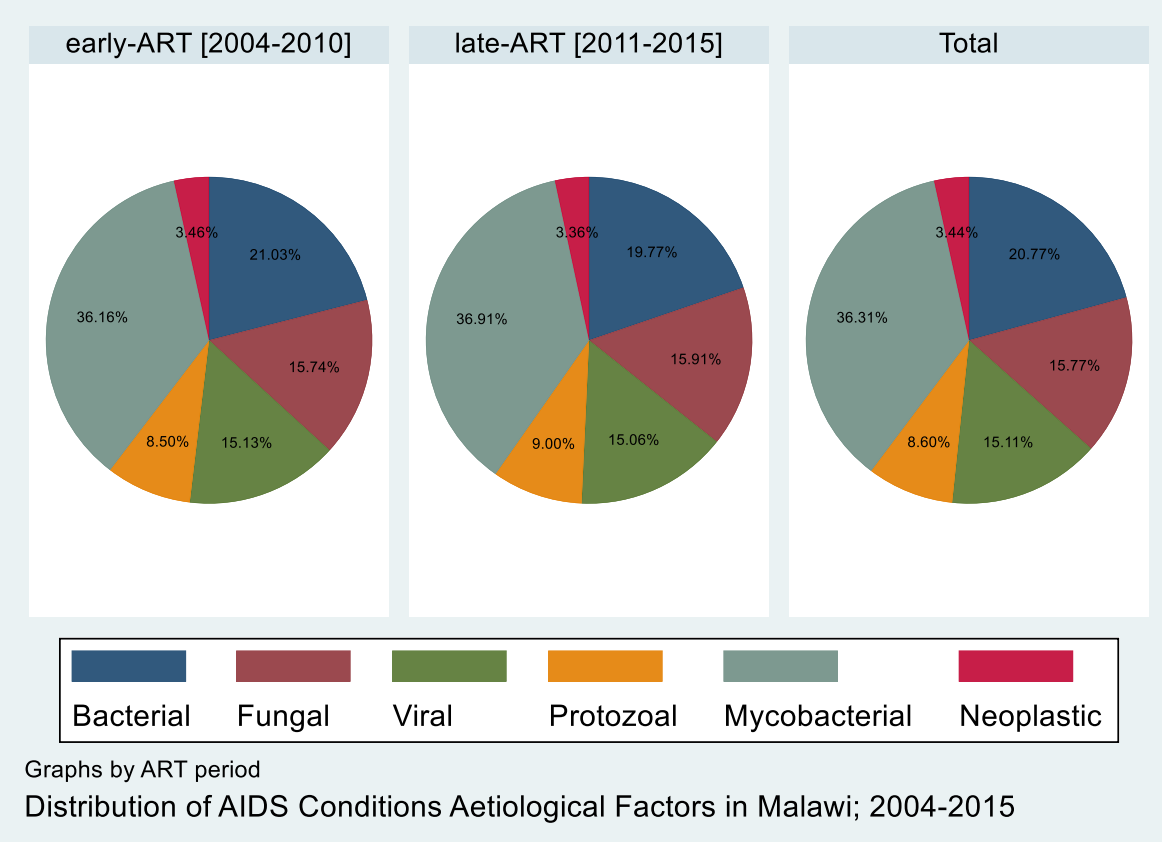

The risk of opportunistic diseases occurring ranged from 1-4 times per patient. Most patients

$289(60.25 \%)$ had only a single AIDS event episode, $29.17 \%$ had dual-AIDS event episodes

290 whereas $2.01 \%$ and $0.92 \%$ had triple and quadruple opportunistic disease event episodes

291 respectively (Fig. 3).

292

293 Figure 3: Frequency of AIDS opportunistic events per patient

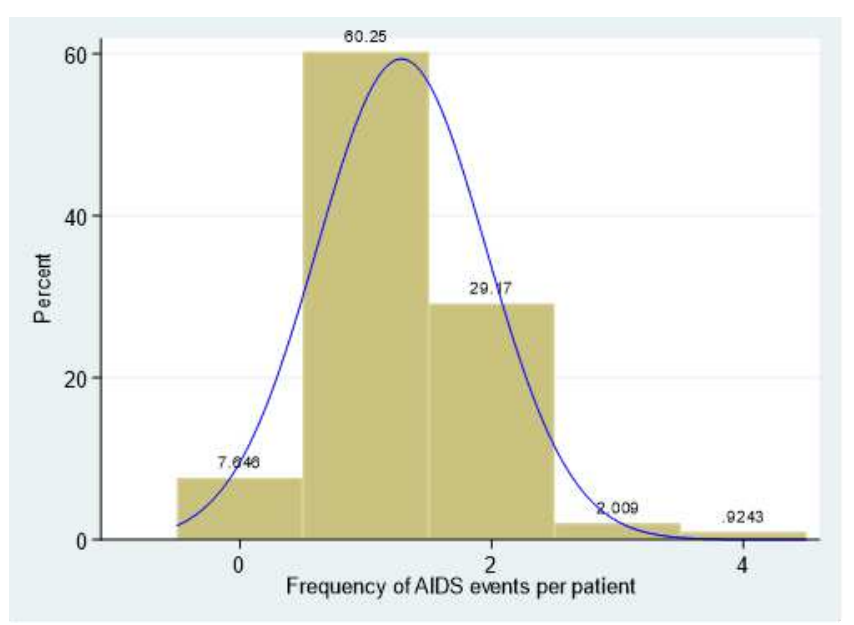


295 Most AIDS event episodes (67.68\%), were diagnosed in tertiary health facilities while 296 secondary and primary facilities accounted for $24.94 \%$ and $7.38 \%$ respectively. Figure 4

297 illustrates frequencies of new HIV-seropositive cases and frequency of opportunistic diseases 298 stratified by year of enrolment (admission) into HIV care. 16.44\% ( $\mathrm{N}=1,636)$ of HIV cases

299 were diagnosed before 2004 (outside the study period). Within the study period, high new HIV 300 cases were registered into care between Jan 2005 and Dec 2007 with rates of $11.27 \%$, 12.76\% 301 and $12.56 \%$ respectively. Likewise, OD events rates were higher in 2006 (12.96\%) followed 302 by 2005 rates but were least in $2015(1.62 \%)$.

304 Figure 4: Frequency of HIV diagnosis cases and ODs by enrolment year; 2004-2015

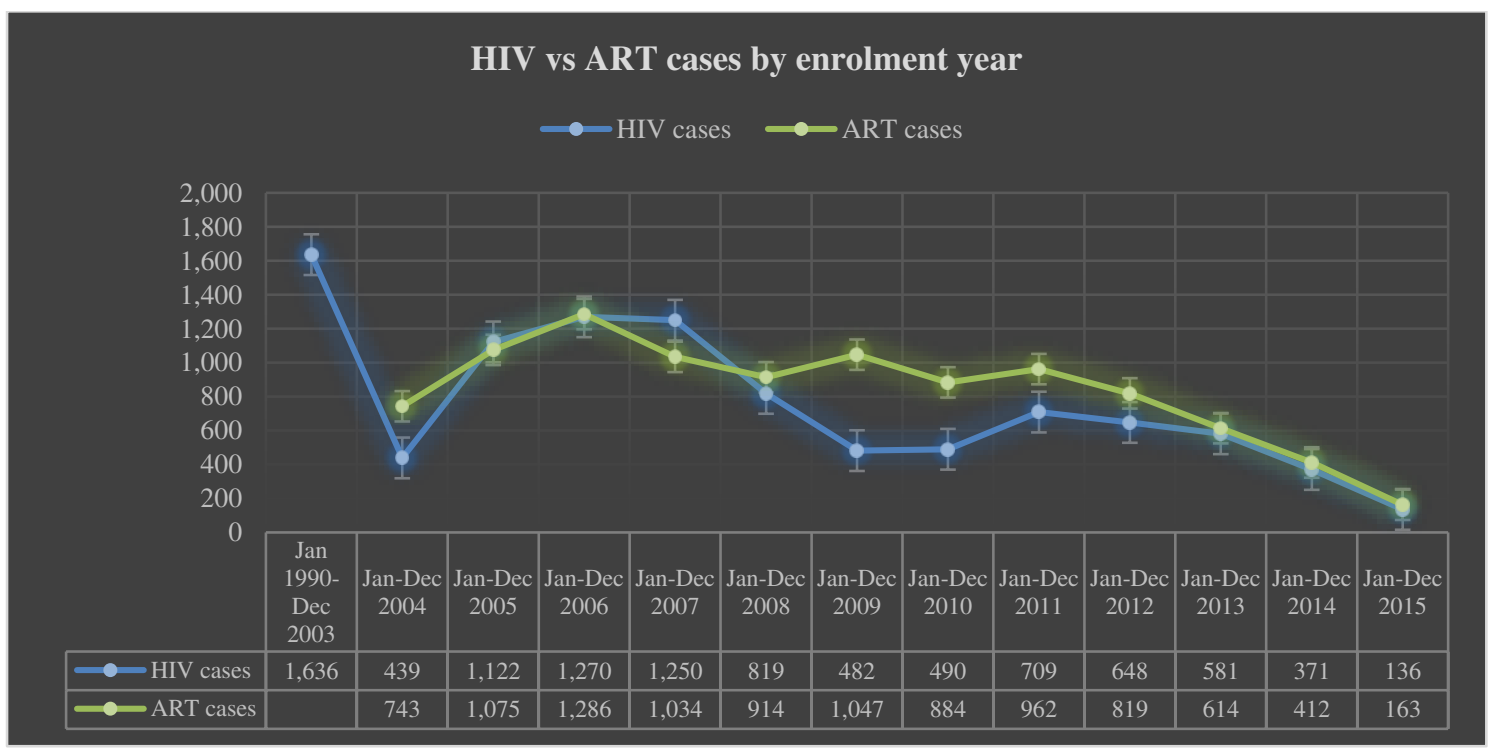

306 The Prevalence of Opportunistic Diseases

307 The frequency of opportunistic diseases among enrolled patients is given in Table 3. Overall, 308 tuberculosis (TB) was most prevalent OD (35.39\%). Based on clinical classification of TB,

309 pulmonary tuberculosis (PTB) was more prevalent (20.44\%) than extrapulmonary type (EPTB,

$3101395 \%$ ). Other most occurring ODs included bacterial pneumonia (11.53\%), non-typhoid 
311 salmonella bacteraemia (9.85\%), HIV wasting syndrome (9.02\%), candidiasis (7.01\%),

312 isosporiasis (5.17\%), pneumocystis pneumonia (4.02\%) and cryptococcal meningitis (3.72\%).

313

314 Table 3: Frequency of ADI Events Stratified for ART-Initiation Period and Health Facility Type

\begin{tabular}{|c|c|c|c|c|c|c|c|}
\hline & Overall & $\begin{array}{l}\text { Early-ART } \\
(2004-2011)\end{array}$ & $\begin{array}{l}\text { Late-ART } \\
(2011-2015\end{array}$ & $\begin{array}{l}\text { Tertiary } \\
\text { healthcare } \\
\text { facilities }\end{array}$ & $\begin{array}{l}\text { Secondary } \\
\text { healthcare } \\
\text { facilities }\end{array}$ & $\begin{array}{l}\text { Primary } \\
\text { healthcare } \\
\text { facilities }\end{array}$ & $\begin{array}{c}\text { OR }(95 \% \mathrm{CI}): \\
\text { primary \& } \\
\text { secondary rates Vs } \\
\text { tertiary h/facilities }\end{array}$ \\
\hline AIDS condition & $\begin{array}{c}\text { Frequency } \\
(\%)\end{array}$ & $\begin{array}{c}\text { Frequency } \\
(\%)\end{array}$ & $\begin{array}{c}\text { Frequency } \\
(\%)\end{array}$ & $\begin{array}{c}\text { Frequency } \\
(\%)\end{array}$ & $\begin{array}{c}\text { Frequency } \\
(\%)\end{array}$ & $\begin{array}{c}\text { Frequency } \\
(\%)\end{array}$ & \\
\hline M. Tuberculosis & $4392(34.39)$ & $3482(34.20)$ & $910(35.14)$ & $3027(25.75)$ & $1019(24.53)$ & $346(27.20)$ & $1.11(1.02,1.21)^{* *}$ \\
\hline Pulmonary tuberculosis & $2611(20.44)$ & $2067(20.30)$ & $544(21.00)$ & $1853(21.23)$ & $553(17.63)$ & $205(22.14)$ & $1.23(1.12,1.36)^{* *}$ \\
\hline $\begin{array}{l}\text { Extrapulmonary } \\
\text { tuberculosis }\end{array}$ & $1781(13.95)$ & $1415(13.89)$ & $366(11.13)$ & $1174(13.45)$ & $466(14.86)$ & $141(15.23)$ & $0.91(0.81,0.98)^{* * *}$ \\
\hline Bacterial pneumonia & $1431(11.53)$ & $1156(11.35)$ & $275(10.62)$ & $937(7.97)$ & $406(9.77)$ & $88(6.92)$ & $0.89(0.79,0.98)^{* *}$ \\
\hline $\begin{array}{l}\text { Nontyphoid Salmonella } \\
\text { bacteraemia }\end{array}$ & $1222(9.85)$ & $985(9.67)$ & $237(9.15)$ & $793(6.75)$ & $352(8.47)$ & $77(6.05)$ & $0.87(0.76,0.98)^{* *}$ \\
\hline HIV-wasting syndrome & $1140(9.02)$ & $914(8.98)$ & $226(8.73)$ & $738(6.28)$ & $314(7.56)$ & $88(6.92)$ & $0.86(0.76,0.98)^{* *}$ \\
\hline Candidiasis & $870(7.01)$ & $694(6.82)$ & $176(6.80)$ & $588(5.00)$ & $214(5.15)$ & $68(5.35)$ & $0.99(0.85,1.15)$ \\
\hline Isosporiasis & $669(5.17)$ & $527(5.18)$ & $142(5.48)$ & $460(3.91)$ & $167(4.02)$ & $42(3.30)$ & $1.05(0.89,1.24)$ \\
\hline Pneumocystis pneumonia & $513(4.02)$ & $407(4.00)$ & $106(4.09)$ & $364(3.10)$ & $117(2.82)$ & $32(2.52)$ & $1.18(1.09,1.43)^{* *}$ \\
\hline Cryptococcal meningitis & $475(3.72)$ & $385(3.78)$ & $90(3.47)$ & $332(2.82)$ & $114(2.74)$ & $29(2.28)$ & $1.11(1.09,1.36)^{* *}$ \\
\hline Cryptosporidiosis & $376(2.94)$ & $293(2.88)$ & $83(3.20)$ & $266(2.26)$ & $81(1.95)$ & $29(2.28)$ & $1.61(0.93,1.45)$ \\
\hline Herpes Simplex virus & $300(2.35)$ & $247(2.43)$ & $53(2.05)$ & $198(1.68)$ & $81(1.95)$ & $21(1.65)$ & $0.92(0.73,1.18)$ \\
\hline Kaposi's Sarcoma (KS) & $298(2.33)$ & $242(2.38)$ & $56(2.16)$ & $199(1.69)$ & $72(1.73)$ & $27(2.12)$ & $0.96(0.75,1.22)$ \\
\hline $\begin{array}{l}\text { Nontuberculous } \\
\text { mycobacteria (NTM) }\end{array}$ & $245(1.92)$ & $199(1.95)$ & $46(1.78)$ & $169(1.44)$ & $56(1.35)$ & $20(1.57)$ & $1.06(0.81,1.40$ \\
\hline Cytomegalovirus infection & $160(1.25)$ & $114(1.12)$ & $46(1.78)$ & $146(1.24)$ & $10(0.24)$ & $21(1.65)$ & $5.07(2.98,8.79)^{* *}$ \\
\hline Mycosis & $156(1.22)$ & $116(1.14)$ & $40(1.54)$ & $138(1.17)$ & $12(0.29)$ & $6(0.47)$ & $3.72(2.27,6.09)^{* *}$ \\
\hline HIV-encephalopathy & $137(1.07)$ & $108(1.06)$ & $29(1.12)$ & $100(0.85)$ & $34(0.82)$ & $3(0.24)$ & $1.30(1.18,1.89)^{* *}$ \\
\hline Invasive Cervical Cancer & $108(0.85)$ & $82(0.81)$ & $26(1.00)$ & $81(0.69)$ & $20(0.48)$ & $7(0.55)$ & $1.43(1.39,2.23)^{* *}$ \\
\hline HIV-cardiomyopathy & $82(0.64)$ & $67(0.66)$ & $15(0.58)$ & $52(0.44)$ & $28(0.67)$ & $2(0.16)$ & $0.83(0.53,1.30)$ \\
\hline HIV-nephropathy & $69(0.54)$ & $54(0.53)$ & $15(0.58)$ & $49(0.42)$ & $15(0.36)$ & $5(0.39)$ & $1.17(0.70,1.97)$ \\
\hline Toxoplasmosis & $53(0.42)$ & $45(0.44)$ & $8(0.31)$ & $40(0.34)$ & $6(0.14)$ & $7(0.55)$ & $1.47\left(1.38,2.76^{* *}\right.$ \\
\hline $\begin{array}{l}\text { Progressive multifocal } \\
\text { leukoencephalopathy }\end{array}$ & $42(0.33)$ & $36(0.35)$ & $6(0.23)$ & $29(0.25)$ & $7(0.17)$ & $6(0.47)$ & $1.07(0.55,2.05)$ \\
\hline Non-Hodgkin's lymphoma & $33(0.26)$ & $28(0.28)$ & $5(0.19)$ & $21(0.18)$ & $10(0.24)$ & $2(0.16)$ & $0.83(0.41,1.70)$ \\
\hline Totals & $\begin{array}{l}12,814 \\
(100 \%)\end{array}$ & $\begin{array}{l}10,181 \\
(100 \%)\end{array}$ & $\begin{array}{l}2,590 \\
(100 \%)\end{array}$ & $\begin{array}{l}8,727 \\
(100 \%)\end{array}$ & $\begin{array}{l}3,135 \\
(100 \%)\end{array}$ & $\begin{array}{l}926 \\
(100 \%)\end{array}$ & -- \\
\hline
\end{tabular}

** statistically significant odds ratio of primary \& secondary health facilities' rates Vs tertiary health facilities 
315 Most AIDS conditions tended to be diagnosed in tertiary health facilities compared to primary

316 and secondary facilities combined. Thus, mycobacterial tuberculosis [OR=1.11, 95\% CI: (1.02,

317 1.21)], cytomegalovirus infection: [OR=5.07, 95\% CI: $(2.98,8.79)]$, mycosis [OR=3.72, 95\%

318 CI: $(2.27,6.09)]$, toxoplasmosis [OR=1.47, 95\% CI: $(1.38,2.76)]$, HIV encephalopathy

$319[\mathrm{OR}=1.30,95 \% \mathrm{CI}:(1.18,1.89)]$ and invasive cervical cancer $[\mathrm{OR}=1.43,95 \% \mathrm{CI}:(1.39,2.23)$.

320 In a general viewpoint, the estimated OD prevalence during early-ART (2004-2011) and late-

321 ART (2011-2015) periods mostly proportionally indifferent. For example, TB prevalence during early-ART was $34.2 \%$ compared to $35.14 \%$ during late-ART while candidiasis was $6.82 \%$ versus $6.8 \%$ for early-ART and late-ART periods, respectively.

PREDICTORS AND RISK FACTORS OF AIDS OPPORTUNISTIC DISEASE EVENTS BASED ON AETIOLOGICAL FACTORS.

\section{Factors Associated with AIDS-related Bacterial Opportunistic Diseases}

The crude and adjusted associations of AIDS-related bacterial disease manifestation are given in Table 4. AIDS-associated bacterial diseases include bacterial pneumonia and nontyphoid Salmonella bacteraemia. In the multivariable regression analysis, health facility level, residential and regional areas, marital and employment status, treatment initiation criteria, CD4 cell count and viral load levels, remained statistically significantly associated with manifestations of bacterial opportunistic conditions. Such that, patients from secondary level

335 health facilities were $34 \%$ more likely to have had bacterial ODs compared to those from 336 primary level facilities [aOR 1.34, 95\% CI: $(1.08,1.66)]$. Urban residents were $15 \%$ more likely to manifest bacterial conditions compared to rural residents [aOR 1.15, 95\% CI: (1.01, 338 1.30)]. Compared with patients from central region, those from southern region were $9 \%$ more 339 likely: [aOR 1.09, 95\% CI: $(1.07,1.23)]$, whereas those from northern region were $21 \%$ less 
340 likely [aOR $0.79,95 \%$ CI: $(0.67,0.94)]$ to manifest bacterial conditions. Ever-single patients

341 had $51 \%$ higher probability of bacterial conditions than previously married ones, [aOR 1.51,

342 95\% CI: $(1.20,1.90)]$ and self-employed patients were $12 \%$ less likely to manifest bacterial

343 conditions [aOR $0.88,95 \%$ CI: $(0.79,0.97)]$.

345 Compared to patients who commenced treatment due to low CD4 count, those advanced 346 disease: clinical stage III of HIV were > 2 times more likely, [aOR 2.22, 95\% CI: (1.93, 2.55)]

347 and those with clinical stage IV were nearly 2 times more likely, [aOR 1.98, 95\% CI: (1.71, 348 2.31)] to have had bacterial OD manifestation. Consequently, increased recent subsequent CD4 349 count of $>1000$ cells $/ \mu \mathrm{L}$ was associated with $10 \%$ reduction in the manifestation of bacterial 350 ODs compared to having CD4 count $<500$ cells $/ \mu \mathrm{L}$, [aOR 0.90, 95\% CI: $(0.76,0.96)$ ]. 351 Likewise, patients with high initial (baseline) viral failure of $>1000$ copies $/ \mathrm{mL}$ were $92 \%$ more 352 likely to have bacterial condition compared to those with VL $<1000$ copies $/ \mathrm{mL}$. Treatment 353 defaulters were $24 \%$ more likely to have had bacterial conditions than patients continuing with 354 treatment (aOR 1.24, 95\% CI: $(1.02,1.49)$.

\section{Factors Associated with AIDS-related Fungal Opportunistic Diseases}

357 Fungal opportunistic conditions accounted for $15.68 \%$ of all AIDS-conditions and include candidiasis, pneumocystis pneumonia, cryptococcal meningitis and mycosis. The crude and adjusted associations of AIDS-related fungal disease manifestations are given in Table 4. In

360 the multivariable analysis, patients from secondary and tertiary healthcare facilities were $33 \%$,

361 [aOR 1.33, 95\% CI: $(1.26,4.91)$, nearly 41/2 times more likely to manifest fungal AIDS362 condition, aOR, 4.42, 95\% CI: $(1.38,14.07)]$, compared to patients in primary facilities. 363 Compared with patients from rural areas, the risk of fungal conditions was increased by $15 \%$ 364 and 52\% among patients from urban and semi-urban areas, [aOR 1.15, 95\% CI: $(1.09,1.93)$ 
and $\mathrm{aOR}=1.52,95 \% \mathrm{CI}:(1.48,2.76)]$ respectively. Patients with advanced HIV disease:

clinical stage III and stage IV at commencement of antiretroviral treatment were $18 \%$ and $85 \%$

more likely to have had a fungal OD, [aOR 1.18, 95\% CI: $(1.03,1.36)]$, and [aOR 1.85, 95\%

CI: $(1.59,2.16)]$ respectively, compared to patients who commenced treatment due to low CD4 count. Patients with initial CD4 count $>250$ cells/ $\mu \mathrm{L}$ were $49 \%$ less likely to have had fungal disease compared to those with $<250$ cells $/ \mu \mathrm{L}$, [aOR $0.59,95 \%$ CI: $(0.52,0.66)]$. Similarly, patients with recent subsequent CD4 count between 500-1000 cells $/ \mu \mathrm{L}$ and $>1000$ cells $/ \mu \mathrm{L}$, were both less likely to have had fungal opportunistic diseases, [aOR $0.61,95 \% \mathrm{CI}:(0.38,0.98)$ and aOR $0.68,95 \% \mathrm{CI}:(0.38,0.73)]$ respectively, compared to those with $<500$ cells $/ \mu \mathrm{L}$ recent CD4 count. Consequently, the likelihood of fungal OD manifestation was increased by $70 \%$ among patients with >1000 copies/mL baseline (initial) viral load compared to those with $<1000$ copies $/ \mathrm{mL}$, [aOR 1.70, 95\% CI: $(1.23,2.35)]$. Other factors with increased risk of fungal conditions were 20-39 years age-group (7\%) compared to 15-19 years old and being married (9\%) compared to previously married. However, having primary or secondary education attainment were both associated with reduced risk of fungal diseases by $3 \%$ and $7 \%$, respectively, compared to patients with no education attainment. Compared to treatment compliant, noncompliant patients: defaulters or lost-to-follow-up (LTFU) was $78 \%$ more likely to have had fungal condition [aOR $1.78,95 \% \mathrm{CI}:(1.64,1.97)]$.

\section{Factors Associated with AIDS-related Viral Opportunistic Diseases}

Viral diseases accounted for $14.4 \%$ of all AIDS-events in this study. In the multivariable analysis outlines in Table 5, patients attending secondary and tertiary health facilities were respectively, approximately 4 times and 5 times more likely to have had viral ODs, [aOR 3.72, 95\% CI: $(1.88,15.79)$ and $4.72,95 \% \mathrm{CI}:(1.15,19.32)]$, compared to those attending primary 
level health facilities. Equally, compared to rural residents, patients from semi-urban and urban areas were $23 \%$ and $13 \%$ more likely to have had viral disease, [aOR $1.23,95 \%$ CI: $(1.02$, $1.48)$ and aOR $1.13,95 \%$ CI: $(1.08,2.48)]$. Similarly, patients from southern region were $14 \%$ more likely to manifest viral diseases compared to those from central region, [aOR $1.14,95 \%$ CI: $(1.01,1.30)]$ and married patients were $95 \%$ more likely to have had viral OD than previously married patients, [aOR 1.95, 95\% CI: $(1.81,3.51)$ ]. Compared to patients initiated cART for low CD4 count, those with advanced HIV disease; clinical stage III and stage IV, were respectively $43 \%$ and $75 \%$ more likely to have had a viral OD: [aOR 1.43, 95\% CI: (1.23, 1.65), and [aOR 1.75, 95\% CI: $(1.49,2.06)]$.

Patients with initial severe viraemia: baseline VL >1000 copies/mL were $92 \%$ more likely to have had viral condition compared to those with <1000 copies/mL, [aOR 1.92, 95\% CI: $(1.67$, 2.28)]. Likewise, patients with recent subsequent suppressed viraemia: VL between 40-1000 copies/mL, were $37 \%$ more likely to have had viral OD, [aOR 1.37, 95\% CI: $(1.29,2.04)$ whilst those with severe viraemia: VL >1000 copies/mL, over 2 times more likely [aOR=2.23, 95\% manifestation was increased by $79 \%$ and $83 \%$ with HIV duration of $6-10$ years and $>10$ years, respectively compared to patients with shorter HIV duration of $<2$ years, [aOR $1.79,95 \% \mathrm{CI}$ : $(1.43,2.46)]$ and [aOR 1.83, 95\% CI: $(1.41,3.68)]$.

408

The odds of manifesting viral ODs were reduced by $27 \%$ and $26 \%$ among patients aged 20-39 years and 40-54 years compared to those aged 15-19 years and by $31 \%$ in individuals with

411 higher education level compared to those with no education, [aOR 0.39, 95\% CI: (0.35, 0.97)].

412 Patients initiated treatment under the universal Option B+/PMTCT criteria were 35\% less 413 likely to manifest viral ODs compared to those commenced treatment because of having low 
414 CD4 count, [aOR 0.65, 95\% CI: $(0.42,0.91)$ ], and by $11 \%$ among patients with recent 415 subsequent CD4 count $>1000$ cells/ $\mu \mathrm{L}$ than those with $100-500$ cells $/ \mu \mathrm{L}$.

416

\section{Factors Associated with AIDS-related Mycobacterial Opportunistic Diseases}

418 Mycobacterial opportunistic diseases accounted for $37.24 \%$ of all AIDS-conditions in the study 419 and they include both types of mycobacterium tuberculosis (TB) and non-tuberculous 420 mycobacteria (NTM). In the multivariable logistic regression analysis outlined in Table 5, 421 mycobacterial conditions were statistically significantly increased by $8 \%$ among patient from 422 northern region compared to those from central region, [aOR 1.08, 95\% CI: $(1.04,1.23)]$. The 423 prevalence was likewise increased by $16 \%, 18 \%$ \& $23 \%$ among individuals with primary, 424 secondary, and higher levels of education compared to those without education $(p<0.05)$. 425 Likewise, mycobacterial OD occurrence was increased by 3-fold and 73\% in patients with 426 clinical stage III and stage IV at treatment initiation, [aOR 3.13, 95\% CI: (2.80, 3.49)], and 427 [aOR 1.73, 95\% CI: $(1.1 .53,1.96)]$ compared to those with low CD4 count. Correspondingly, 428 the likelihood of mycobacterial condition manifestation was increased by $21 \%$ in patients with 429 initial baseline VL $>1000$ copies $/ \mathrm{mL}$ compared to those with $<1000$ copies $/ \mathrm{mL}$ and by $51 \%$ in 430 those receiving non-standard ART regimen as maintenance treatment than those maintained on 431 Nevirapine-based regimens, [aOR 1.51, 95\% CI: (1.03, 2.19)]. Compared to patients with 1-2 432 years HIV duration, those with 3-5 years, 6-10 years and >10 years of living with HIV were $43310 \%, 12 \%$ and $19 \%$ more likely to have had AIDS-related mycobacterial opportunistic 434 conditions.

436 In contrast, the probability of mycobacterial opportunistic disease occurrence was reduced by $43725 \%$ among patients with initial CD4 count $>250$ cells/ $\mu \mathrm{L}$ compared to those with $<250$ 
cells $/ \mu \mathrm{L}$, aOR $0.75,95 \% \mathrm{CI}:(0.55,0.96)]$. The probability was equally reduced by $23 \%$ and $15 \%$ in secondary and tertiary hospital health facilities compared to patients in primary level health facilities, [aOR 0.77, 95\% CI: $(0.64,0.92)$ and aOR $0.85,95 \% \mathrm{CI}:(0.72,0.91)]$ and by $55 \%$ among patients initiated treatment due to Option B+/PMTCT than those initiated due to low CD4 count, [aOR 0.45, 95\% CI: $(0.32,0.64)]$.

\section{Factors Associated with AIDS-related Protozoal (Parasitic) Opportunistic Diseases}

The crude and adjusted regression analysis results of protozoal diseases are summarized in

446 Table 6. AIDS-defining protozoal conditions include cryptosporidiosis, isosporiasis and toxoplasmosis and accounted for $8.2 \%$ of all AIDS events in this study. In the multivariable analysis, male patients were $5 \%$ more likely to have had protozoal conditions compared to females, [aOR 1.05, 95\% CI: $(1.02,1.25)]$. Similarly, office-based workers were $26 \%$ more likely to have had protozoal conditions than manual workers; [aOR 1.26, 95\% CI: $(1.05,1.58)]$. Patients with stage III and stage IV of HIV disease at ART initiation were $36 \%$ and $26 \%$ respectively, more likely to manifest protozoal OD compared to those initiated treatment due to low CD4 count, [aOR 1.36, 95\% CI: $(1.1 .13,1.64)]$ and [aOR 1.26, 95\% CI: $(1.02,1.56)]$. Patients with high initial viral failure: VL>1000 copies/mL were $15 \%$ more likely to have had protozoal condition than those with VL<1000 copies/mL, [aOR 1.15, 95\% CI: $(1.07,1.79)]$.

Furthermore, patients on non-standard ART maintenance regimens were $78 \%$ more probable to have had protozoal infections compared to those maintained on nevirapine-based regimens, [aOR 1.78, 95\% CI: $(1.08,2.93)]$. Above the expectation, patients with $>10$ years treatment

460 duration were $71 \%$ more probable to have had a protozoal disease compared to those with $<2$ years on treatment, [aOR 1.71, 95\% CI: $(1.05,3.08)]$. 
462 In contrast, the probability of protozoal OD manifestation significantly reduced by $35 \%, 32 \%$ 463 and 44\% among patients aged 20-39 years, 40-54 years, and 55+ years old compared to those 464 aged 15-19 years. Likewise, the probability was reduced by $19 \%$ and $23 \%$ among patients with 465 recent subsequent CD4 count between 500-1000 cells/ $\mu \mathrm{L}$ and $>1000$ cells $/ \mu \mathrm{L}$ compared with 466 those with $<500$ cells $/ \mu \mathrm{L}$. Equally, patients commenced treatment with Efavirenz-based 467 regimens had $17 \%$ less likelihood of manifesting protozoal conditions compared to those 468 commenced on Nevirapine-based regimens, [aOR 0.83, 95\% CI: $(0.71,0.97)]$.

\section{Factors Associated with AIDS-related Neoplastic Opportunistic Diseases}

471 AIDS-related opportunistic neoplastic diseases accounted for only $3.1 \%$ of all AIDS events in the study. They include invasive cervical cancer, Kaposi' sarcoma and non-Hodgkin lymphoma (WHO, 2007). The crude and adjusted associations of AIDS-related bacterial disease manifestation are given in Table 6.

In the multivariable analysis, patients from secondary and tertiary health facilities were $86 \%$ and $94 \%$ more likely to have had opportunistic neoplasm compared to those attending primary health facilities, [aOR 1.86, 95\% CI: $(1.55,2.35)$ and aOR 1.94, 95\% CI: $(1.63,2.42)]$. Smallscale unskilled workers were $48 \%$ more likely to have had neoplasm compared to those doing manual work, [aOR 1.48, 95\% CI: $(1.05,2.08)]$. Equally, compared to patients initiated treatment for low CD4 count, those who had advanced HIV disease - WHO clinical stage IV were over 3 times more likely to have had opportunistic neoplasm, [aOR 3.24, 95\% CI: (2.46, 4.27)]. Patients with initial baseline VL >1000 copies/mL were $74 \%$ more likely to have had HIV-related cancer than those with <1000 copies/mL, [aOR 1.74, 95\% CI: $(1.39,2.40)]$. 
486 In contrast, the probability of opportunistic neoplasms were significantly reduced by $27 \%$ in 487 males compared to females, [aOR $0.73,95 \%$ CI: $(0.56,0.95)]$; by $42 \%$ among ever-single

488 patients compared to previously married. Patients who commenced treatment because of 489 universal Option B+/PMTCT criteria had 77\% reduced probability of manifesting neoplasm 490 [aOR 0.23, 95\% CI: $(0.06,0.96)$. Similarly, those commenced under clinical stage III of HIV 491 had $31 \%$ reduced probability [aOR $0.69,95 \%$ CI: $(0.49,0.97)$ ] compared to those started 492 treatment due to low CD4 count.

\section{DISCUSSION}

This retrospective chart review study has elucidated common types and magnitude of opportunistic diseases prevailing among adult PLHIV in Malawi on combined antiretroviral therapy. The study has also outlined factors associated with the manifestation of AIDS-related opportunistic diseases aetiological agents.

500 Participants were once commenced on regular ART under the national standardised treatment

501 protocol between 2004-2015. We extracted all AIDS-related conditions that are traditionally AIDS-defining (both incident and prevalent cases) that occurred among the enrolled patients during the 11 year data generation period. Opportunistic events frequency ranged from 1- 4 times per patient such that $60.25 \%, 29.17 \%, 2.01 \%$ and $0.92 \%$ of patients had single, dual, 505 triple, and quadruple opportunistic events.

507 The overall cumulative period prevalence of ODs in the present study was remarkably high

$508(128.31 \%)$ due to repeated occurrences. This finding compares with $120.97 \%$ overall 509 prevalence from Taiwan University Hospital study which reported a total of 1,263 OD events 
510 from $(\mathrm{n}=1,044)$ patients (Sun et al., 2006). However, our finding is much lower than $268.06 \%$

511 overall prevalence estimated from TASO HIV facilities in Uganda which reported a total of

512 291,168 OD episodes from (n=108,619) HIV patients from 2001 to 2013 (Rubaihayo et al., 513 2016).

514

515 Of all AIDS-opportunistic events identified in this study $(\mathrm{N}=12,814), 59.01 \%$ were prevalent cases whereas $40.99 \%$ were incident cases. Therefore, the prevalence of incident ODs affecting adult PLHIV on ART in Malawi between 2004 and 2015 was an estimated $55.76 \%$ with repeated occurrences. This finding is comparable to $48.0 \%$ prevalence reported in Hiwot Fana

519 Hospital (Mitiku et al., 2015); 42.8\% prevalence reported in Debre Markos Hospital (Moges

$520 \&$ Kassa, 2014) both from Ethiopia. The finding is likewise comparable to $47.6 \%$ prevalence reported from both Taiwan University Hospital (Sun et al., 2006) and from Tshepang Clinic South Africa (Mzileni et al., 2008). However, this finding is relatively higher than $19.7 \%$ prevalence reported in Gondar Hospital (Damtie et al., 2013), 22.4\% prevalence reported in

524 South East Nigeria (Iroezindu, 2013) and 30\% prevalence reported in Bamrasnaradura institute

525 Thailand (Knauer et al., 2005). The observed difference between the current study and studies that reported lower prevalence could be due to methodological differences in subject selection, study period, diagnostic capacity, or degree of host immunity. For example, Gondar Hospital study period was short (February-April, 2012) and involved both treatment naïve and exposed patients, the study from Nigeria was conducted for median duration of 3 years while the

530 Thailand study had a 15 month follow-up period.

532 The present study summarised clinical data representing $1.0 \%$ of people living with HIV in 533 Malawi and $1.03 \%$ of HIV infected adults accessing antiretroviral therapy. Majority were urban 534 residents $(65.08 \%)$ within the productive group of $15-49$ years $(78.22 \%)$ and women $(60.84 \%)$. 
535 Moreover, $82.21 \%$ relied guardian escort to health facility which may signify poor physical condition during initial presentation. Most patients were married (78.74\%), had low education

537 (40.81\%), and were of low socio-economic status (49.72\%) engaged in unskilled jobs although

538 the majority were permanently employed (55.32\%). The nature of patients in the current study 539 is comparable to other studies elsewhere within the sub-Saharan Africa region ART 540 programmes such as Uganda, Ethiopia and South Africa (Iroezindu, 2013; Mageda et al., 2012;

541 Mitiku et al., 2015; Moges \& Kassa, 2014; Rubaihayo et al., 2016; Theuring et al., 2015;

542 Weldegebreal et al., 2018). In a cross-sectional serial review of observational data of adult

543 PLHIV in Uganda, $64 \%$ were found to be women, $77 \%$ were of low education and $76 \%$ had

544 low socio-economic status (Rubaihayo et al., 2016). Likewise, a study in Nigeria which 545 analysed both pre-HAART and post-HAART data found that $65.8 \%$ of subjects were women and half (50.4\%) were of low socio-economic status (Iroezindu, 2013). Furthermore, a health facility-based cross-sectional study in Ethiopia found that $61.8 \%$ were women, $96.2 \%$ were within productive group, $50.8 \%$ were married and $68.6 \%$ had low education ((Weldegebreal et $a l ., 2018)$. The fact that the proportion of women was consistently higher in these studies, including the present one, may imply that men probably remain under-represented in most ART programmes in the SSA with consequently less favourable national programme outcomes. Additionally, this also signify that women remain disproportionately affected by HIV/AIDS.

554 Overall, of all opportunistic events in the current study, opportunistic infections accounted for $55596.9 \%$ compared to $3.1 \%$ of opportunistic neoplastic conditions (cancers); Kaposi' sarcoma, invasive cervical cancer and Non-Hodgkin lymphoma. This finding is consistent with that from Uganda (Rubaihayo et al., 2015). This evidence signifies that opportunistic infections; other than opportunistic neoplasms, are the principal causes of morbidity and mortality among adult PLHIV within the SSA (Staine, 2007). Tuberculosis prevalence in the current study was 
comparatively high (35.39\%) compared to findings from other studies elsewhere (Iroezindu, 2013; Mageda et al., 2012; Mitiku et al., 2015; Moges \& Kassa, 2014; Rubaihayo et al., 2016;

562 Theuring et al., 2015; Weldegebreal et al., 2018). This observed difference was due to high 563 rates of TB in Malawi. With the advent of HIV, Malawi has progressively experienced higher 564 rates of respiratory infections particularly TB (Harries et al., 1998; Kanyerere et al., 2016;

565 Kanyerere et al., 2014; Kwanjana et al., 2001; Warndorff et al., 2000; Zachariah et al., 2003). TB remains to be most common in Malawi with PTB affecting approximately 11,000 people per year (Kalua et al., 2018). Besides, a substantial proportion of TB suspects are AAFB 'smear negative' and hence clinically diagnosed, although some, approximately $17 \%$, may be later culture confirmed (Hargreaves et al., 2001).

570

571 One opportunistic disease; the atypical disseminated leishmaniasis, was not seen in the present study. This suggests either its absence in Malawi or lack of diagnostic capability; however, the former seems likely. Epidemiological evidence shows that there have only been 2 cases of

574 leishmaniasis reported (WHO, 2010a). Both were diagnosed at post-mortem, the first case reported in 1979 and both patients had travelled to Tanzania.

576

577 Accordingly, no opportunistic events were extracted in the current study prior to 2004; before public sector rollout of ART programmes. As expected, the burden of opportunistic conditions during early-ART period (2004-2011), was indeed high; accounting for $79.83 \%$ compared to

$58020.17 \%$ in late-ART (2011-2015). During both periods, mycobacterial agents were common aetiological agents of ODs followed by bacterial, fungal, and viral agents (Fig 3). The most prevalent conditions during early-ART era were tuberculosis (34.2\%), recurrent, severe bacterial pneumonia (11.35\%), nontyphoid Salmonella (NTS) bacteraemia (9.67), HIV wasting 
results was equally similar with that of late-ART period. This might be because these ODs are highly endemic in Malawi and relatively easy to diagnose. Similar conditions were also observed in previous studies across Africa, particularly the Sub-Saharan region (Damtie et al., 2013; Iroezindu, 2013; Mitiku et al., 2015; Moges \& Kassa, 2014).

\section{Study Limitations \& Strengths}

592 To my knowledge, this national representative study was the first to establish and aggregate nationwide information relating to opportunistic diseases among adult PLHIV receiving combined antiretroviral therapy in Malawi. The study has used sufficient sample size with wider geographical coverage (all three regions) and involved all existing health facility types to ensure generalisability. The study has shown the estimated national prevalence level of opportunistic diseases in HIV adult patients, revealed their types, magnitude and factors associated with their occurrences. This was done in a helpful way to inform public health and clinical practice and the procurement and distribution of drugs (for treating ODs) other than ARVs at all healthcare facility levels. Besides, the study has attempted to reflect a true picture of all common ODs prevalent among adult PLHIV in Malawi in that it has included ART-naïve

602 patients qualifying for and commenced on cART with or without OD prophylaxis treatments.

603 These patients were then followed-up for different time periods for as long as they remained in care and their current treatment outcomes documented, - finally giving a picture of ODs in both ART-naïve and ART-experienced patients.

607 However, the fact that the study was conducted using pre-existing medical records 608 retrospectively, it is subjected to limitations. These may emanate from incomplete recording of 609 vital clinical information and diagnostic capability of some collaborating health facilities. Thus, 
610 the study used data collected primarily not for medical research, hence, some variables which

611 would have been vital and helpful in the interpretation of the results like ART adherence,

612 opportunistic disease prophylaxis received, functional status and the clinical surrogate markers

613 were either completely absent or missing for some patients. It is therefore imperative that future

614 (prospective) cohort studies should target those data. Besides, most research collaborating 615 centres had no capability and competence to readily perform cultures or confirmatory diagnosis 616 of ODs. As such, some conditions were diagnosed clinically which would have potentially

617 imparted diagnosis accuracy. Thirdly, the study did not assess pre-ART burden of ODs prior 618 to the 2004 nationwide rollout declaration of cART. As such, the national rate of decline in the 619 burden of ODs due to cART could not be ascertained. Fourthly, some ODs were not captured 620 in some research centres probably due to inadequate diagnostic capability. Besides, a small proportion of all TB cases $(\mathrm{N}=109,2.48 \%)$ were clinically unclassified when retrieved but treated as PTB for consistency. Next, due to limited resources, some potential OD cases seen in lower health facilities; primary (health centres) or secondary (district/faith-based hospitals), were referred to tertiary health facilities. These could have been underestimated or missed as not all referred cases were reaching the referral centres.

\section{CONCLUSION}

630 This study has demonstrated that opportunistic diseases were pervasive among adult PLHIV in

631 Malawi. This imply that ODs remain recognisably clinical and public health challenges. The 632 results, however, show that the frequency and profile of ODs have changed since free cART 633 was rolled-out nationally to all clinically eligible patients. However, the changes are varied by 634 factors such as type of ODs, time period, age-group, gender, and geographical areas. Multiple 
635 aetiological pathogens, in particular mycobacterial causes, continue to dominate as primary

636 causes of serious ODs in Malawi. Precisely, tuberculosis, bacterial pneumonia, nontyphoid

637 Salmonella bacteraemia, HIV-wasting syndrome, candidiasis, isosporiasis and Pneumocystis

638 pneumonia were among most common AIDS-related opportunistic diseases encountered by

639 adult PLHIV. These diseases therefore warrant particular attention and consideration Malawi's

640 HIV/AIDS care programmes. However, this must not be at the expense of other aetiological

641 factors and serious ODs that had relatively low prevalence like KS and ICC. Healthcare facility

642 types, gender, age, geographical location, CD4 cell count and high viraemia, and ART

643 initiation clinical eligibility were commonly occurring independent predictors strongly

644 associated with manifestation of serious ODs. These factors require special consideration when

645 managing HIV patients especially screening for disease progression. Hence, screening and

646 prevention strategies of HIV and ODs need to be redesigned, monitored, and prioritised. The

647 need to strengthen strategies and care models that highlight early identification of new HIV-

648 positive cases and the need for nationwide accelerated implementation of test-and-treat

649 approach cannot be overemphasised. Prophylaxis treatment must be widely implemented and

650 closely monitored in the routine management of people with HIV irrespective of ART use.

651 Additionally, AIDS-related opportunistic diseases diagnostic capabilities need to be

652 strengthened in all centres initiating and monitoring ART.

653

654

655

656

657

658 
660 HS conceived the study, participated in the study design, data collection, analysis, and 661 manuscript writing.

662

663 Acknowledgements

664 The author is grateful to the gate keepers and all research teams that were elected for this study 665 from all 8 research sites: Nkhoma ART facility, Lighthouse Trust \& Martin Preus Centre ART 666 facility, Partners-in-Hope ART facility, Mzuzu ART facility, DREAM centre ART facility, 667 Chiradzulu ART facility, QECH ART facility, and Thyolo ART facility for all the support 668 towards this study.

669

670 Competing interests

671 The author declares that he has no competing interests.

672

673 Availability of data and materials

674 All relevant data generated or analysed during this study are available from the corresponding 675 author on reasonable request.

677 Ethical approval and consent to participate

678 The study obtained ethical approval from the University of Warwick Research Ethics

679 Committee, the Biomedical and Scientific Research Ethics Committee (BSREC)); BSREC 680 approval number: REGO-2015-1576, and from Malawi Research Ethics Committee, the 
681 National Health Sciences Research Committee (NHSRC) under the Ministry of Health;

682 NHSRC approval number: NHSRC \# 16/3/1555. Approval from NHSRC was granted after 683 obtaining "Letters of No Objection" from each of the 8 data collection centres. The need for 684 consent to participate was waived off due to the nature of and source of study's data.

685

686 Abbreviations

ADROC AIDS-defining \& recurrent opportunistic conditions

HAART highly active antiretroviral therapy

cART Combined antiretroviral therapy

HIV human immunodeficiency virus

IQR interquartile range

AIDS acquired immunodeficiency syndrome

OD opportunistic disease/s

OC Opportunistic condition/s

TASO The AIDS Support Organisation

UNAIDS Joint United Nations Programme on HIV/AIDS

WHO World Health Organisation

MDHS Malawi demographic and health survey

687

688 Competing interest

689 The author/s declare that they have no competing interest

$690 \quad$ Funding

691 None [Self-funding as part of academic programme]

692

693 ORCID iD: https://orcid.org/0000-0002-7113-8723

694 
Table 4: Factors Associated with Manifestation of Bacterial and Fungal Opportunistic Diseases in HIV-infected adults in Malawi; 2004-2015

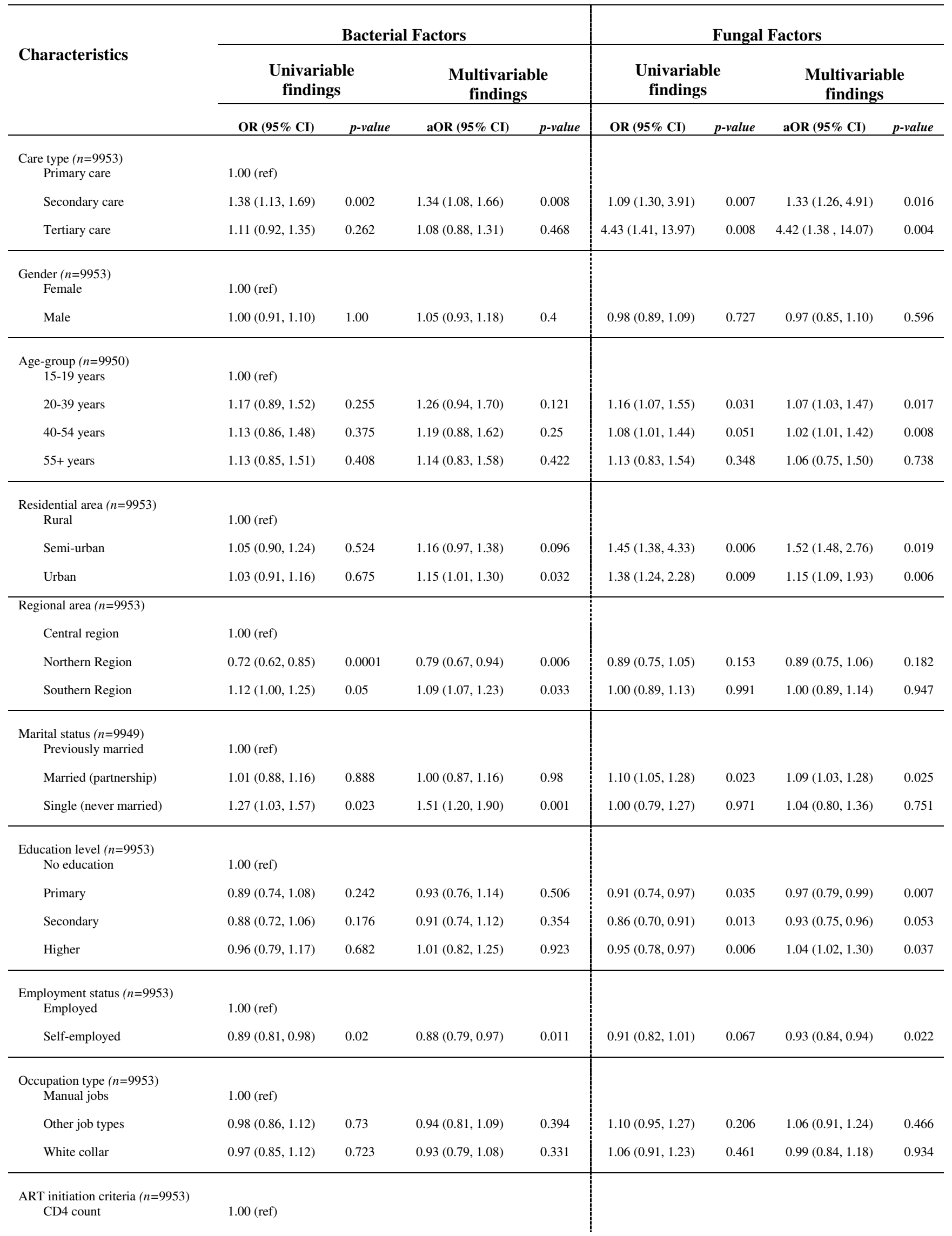




\begin{tabular}{|c|c|c|c|c|c|c|c|c|}
\hline PMTCT & $0.99(0.68,1.42)$ & 0.942 & $1.03(0.71,1.49)$ & 0.87 & $1.11(0.78,1.57)$ & 0.574 & $1.11(0.78,1.58)$ & 0.567 \\
\hline WHO III & $2.13(1.87,2.42)$ & 0.0001 & $2.22(1.93,2.55)$ & 0.0001 & $1.25(1.10,1.43)$ & 0.001 & $1.18(1.03,1.36)$ & 0.02 \\
\hline WHO IV & $1.97(1.70,2.28)$ & 0.0001 & $1.98(1.70,2.31)$ & 0.0001 & $1.89(1.63,2.18)$ & 0.0001 & $1.85(1.59,2.16)$ & 0.0001 \\
\hline \multicolumn{9}{|c|}{ CD4-initial results ( $n=9944)$} \\
\hline$>250$ cells $/ \mu \mathrm{L}$ & $1.00(0.91,1.11)$ & 0.94 & $1.02(0.91,1.13)$ & 0.768 & $0.61(0.54,0.69)$ & 0.0001 & $0.59(0.52,0.66)$ & 0.0001 \\
\hline $\begin{array}{c}\text { CD4-recent results }(n=9) \\
100-500 \text { cells } / \mu \mathrm{L}\end{array}$ & 1.00 (ref) & & & & & & & \\
\hline $501-1000$ cells $/ \mu \mathrm{L}$ & $1.00(0.90,1.11)$ & 0.968 & $1.04(0.90,1.20)$ & 0.612 & $0.65(0.45,0.95)$ & 0.033 & $0.61(0.38,0.98)$ & 0.025 \\
\hline$>1000$ cells $/ \mu \mathrm{L}$ & $0.88(0.76,0.92)$ & 0.051 & $0.90(0.76,0.98)$ & 0.027 & $0.75(0.45,1.24)$ & 0.082 & $0.68(0.38,0.73)$ & 0.009 \\
\hline \multicolumn{9}{|l|}{ VL-initial results $(n=9945)$} \\
\hline$>1000$ copies $/ \mathrm{mL}$ & $1.66(1.24,2.22)$ & 0.001 & $1.92(1.68,2.27)$ & 0.023 & $1.70(1.23,2.35)$ & 0.001 & $1.25(0.89,1.76)$ & 0.196 \\
\hline \multicolumn{9}{|c|}{$\begin{array}{l}\text { VL-recent results }(n=9953) \\
\quad 0-40 \text { copies } / \mathrm{mL}\end{array}$} \\
\hline $41-1000$ copies $/ \mathrm{mL}$ & $0.97(0.86,1.08)$ & 0.543 & $0.97(0.85,1.10)$ & 0.59 & $1.15(1.02,1.30)$ & 0.025 & $1.14(1.00,1.31)$ & 0.052 \\
\hline$>1000-$ copies $/ \mathrm{mL}$ & $0.96(0.86,1.08)$ & 0.489 & $0.87(0.74,1.01)$ & 0.073 & $1.12(0.99,1.26)$ & 0.076 & $1.22(1.04,1.44)$ & 0.016 \\
\hline \multicolumn{9}{|c|}{$\begin{array}{l}\text { Current ART regimen ( } n=9953) \\
\text { Nevirapine-based }\end{array}$} \\
\hline Efavirenz-based & $1.10(0.98,1.23)$ & 0.091 & $1.08(0.96,1.21)$ & 0.206 & $1.08(0.96,1.22)$ & 0.202 & $1.08(0.96,1.22)$ & 0.215 \\
\hline Boosted-Ritonavir & $1.41(1.09,1.83)$ & 0.01 & $1.39(1.06,1.81)$ & 0.016 & $0.80(0.58,1.10)$ & 0.174 & $0.78(0.57,1.09)$ & 0.142 \\
\hline Non-std. & $1.21(0.81,1.83)$ & 0.354 & $1.26(0.83,1.91)$ & 0.277 & $0.68(0.41,1.15)$ & 0.151 & $0.69(0.41,1.17)$ & 0.167 \\
\hline \multicolumn{9}{|l|}{ HIV duration $(n=9953)$} \\
\hline $3-5$ years & $1.15(0.99,1.35)$ & 0.075 & $1.14(0.90,1.44)$ & 0.267 & $0.90(0.76,1.06)$ & 0.194 & $0.91(0.71,1.17)$ & 0.469 \\
\hline $6-10$ years & $1.01(0.87,1.17)$ & 0.918 & $1.02(0.76,1.38)$ & 0.88 & $0.90(0.78,1.05)$ & 0.196 & $0.95(0.68,1.32)$ & 0.751 \\
\hline$>10$ years & $1.05(0.88,1.26)$ & 0.553 & $1.09(0.72,1.66)$ & 0.676 & $0.80(0.66,0.96)$ & 0.018 & $0.89(0.56,0.94)$ & 0.017 \\
\hline \multicolumn{9}{|l|}{ ART duration $(n=9953)$} \\
\hline $3-5$ years & $1.04(0.91,1.18)$ & 0.571 & $1.02(0.83,1.24)$ & 0.881 & $0.94(0.82,1.07)$ & 0.347 & $0.99(0.79,1.24)$ & 0.932 \\
\hline $6-10$ years & $0.90(0.80,1.02)$ & 0.106 & $0.97(0.74,1.27)$ & 0.819 & $0.92(0.81,1.05)$ & 0.238 & $0.98(0.73,1.32)$ & 0.899 \\
\hline$>10$ years & $0.88(0.71,1.09)$ & 0.242 & $0.91(0.62,1.35)$ & 0.649 & $0.78(0.61,0.98)$ & 0.037 & $0.89(0.58,0.93)$ & 0.011 \\
\hline $\begin{array}{l}\text { Clinical latency }(n=9953 \\
1-2 \text { years }\end{array}$ & \multicolumn{8}{|c|}{ Clinical latency $(n=9953)$} \\
\hline $3-5$ years & $1.10(0.99,1.23)$ & 0.084 & $1.05(0.90,1.22)$ & 0.532 & $0.97(0.85,1.09)$ & 0.579 & $1.01(0.86,1.19)$ & 0.91 \\
\hline$>5$ years & $1.09(0.91,1.31)$ & 0.328 & $1.00(0.75,1.32)$ & 0.991 & $0.91(0.75,1.11)$ & 0.355 & $1.00(0.73,1.36)$ & 0.995 \\
\hline $\begin{array}{r}\text { Treatment outcomes }(n= \\
\text { Treatment adherent }\end{array}$ & 1.00 (ref) & & & & & & & \\
\hline Defaulters \& LTFU & $1.12(1.00,1.26)$ & 0.051 & $1.10(1.07,1.24)$ & 0.053 & $1.02(0.90,1.16)$ & 0.109 & $1.19(1.14,1.90)$ & 0.017 \\
\hline Died & $1.29(1.12,1.48)$ & 0.001 & $1.24(1.02,1.49)$ & 0.031 & $0.91(0.77,1.07)$ & 0.258 & $1.78(1.64,1.97)$ & 0.022 \\
\hline
\end{tabular}


Table 5: Factors Associated with Manifestation of Viral and Mycobacterial Opportunistic Diseases in HIV-infected adults in Malawi; 2004-2015

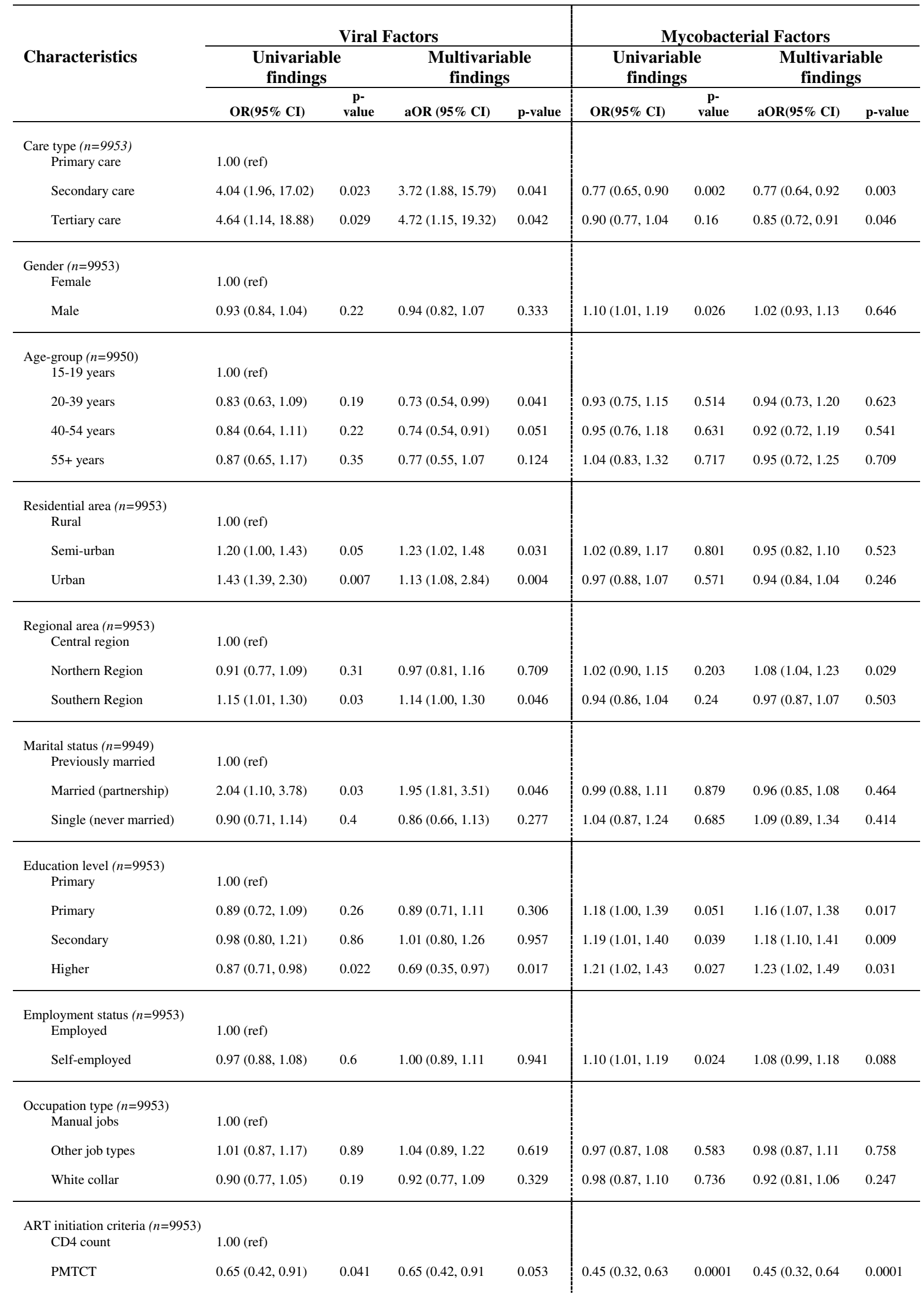




\begin{tabular}{|c|c|c|c|c|c|c|c|c|}
\hline WHO III & $1.39(1.21,1.60)$ & 0.0001 & $1.43(1.23,1.65$ & 0.0001 & $2.93(2.65,3.25$ & 0.0001 & $3.13(2.80,3.49$ & 0.0001 \\
\hline WHO IV & $1.74(1.50,2.03)$ & 0.0001 & $1.75(1.49,2.06$ & 0.0001 & $1.63(1.45,1.84$ & 0.0001 & $1.73(1.53,1.96$ & 0.0001 \\
\hline $\begin{array}{c}\text { CD4-initial results }(n=99 \\
0-250 \text { cells } / \mu \mathrm{L}\end{array}$ & 1.00 (ref) & & & & & & & \\
\hline$>250$ cells $/ \mu \mathrm{L}$ & $1.08(0.97,1.21)$ & 0.18 & $1.07(0.96,1.20$ & 0.217 & $1.05(0.96,1.15$ & 0.255 & $1.15(1.05,1.26$ & 0.003 \\
\hline $\begin{array}{c}\text { CD4-recent results }(n=99 \\
100-500 \text { cells } / \mu \mathrm{L}\end{array}$ & 1.00 (ref) & & & & & & & \\
\hline $501-1000$ cells $/ \mu \mathrm{L}$ & $1.05(0.93,1.18)$ & 0.46 & $1.10(0.94,1.29$ & 0.217 & $1.01(0.93,1.11$ & 0.785 & $0.93(0.82,1.05$ & 0.247 \\
\hline$>1000$ cells $/ \mu \mathrm{L}$ & $0.95(0.81,0.98)$ & 0.015 & $0.89(0.82,0.97$ & 0.028 & $1.08(0.96,1.22$ & 0.194 & $0.98(0.84,1.14$ & 0.764 \\
\hline $\begin{array}{c}\text { VL-initial results }(n=994 \\
<1000 \text { copies } / \mathrm{mL}\end{array}$ & 1.00 (ref) & & & & & & & \\
\hline$>1000$ copies $/ \mathrm{mL}$ & $1.32(1.17,1.79)$ & 0.008 & $1.92(1.67,2.28)$ & 0.016 & $1.66(1.33,2.08$ & 0.0001 & $1.79(1.62,1.91$ & 0.052 \\
\hline $\begin{array}{c}\text { VL-recent results }(n=995 \\
0-40 \text { copies } / \mathrm{mL}\end{array}$ & 1.00 (ref) & & & & & & & \\
\hline $41-1000$ copies $/ \mathrm{mL}$ & $1.37(1.92-2.03)$ & 0.016 & $1.37(1.29-2.04)$ & 0.027 & $0.96(0.88,1.06$ & 0.45 & $0.96(0.86,1.07$ & 0.49 \\
\hline$>1000$ copies $/ \mathrm{mL}$ & $2.26(1.84-2.89)$ & 0.007 & $2.23(1.82-2.55)$ & 0.042 & $0.95(0.86,1.04$ & 0.26 & $0.94(0.83,1.08$ & 0.38 \\
\hline $\begin{array}{c}\text { Current ART regimen ( } n \\
\text { Nevirapine-based }\end{array}$ & 1.00 (ref) & & & & & & & \\
\hline Efavirenz-based & $0.88(0.78,0.99)$ & 0.04 & $0.87(0.77,0.98$ & 0.021 & $0.94(0.86,1.03$ & 0.212 & $0.96(0.87,1.06$ & 0.411 \\
\hline Boosted-Ritonavir & $0.93(0.69,1.26)$ & 0.66 & $0.92(0.68,1.25$ & 0.606 & $1.04(0.83,1.31$ & 0.719 & $1.00(0.78,1.27$ & 0.979 \\
\hline Non-std. & $0.70(0.42,1.16)$ & 0.16 & $0.71(0.42,1.18$ & 0.184 & $1.46(1.03,2.09$ & 0.035 & $1.51(1.04,2.19$ & 0.029 \\
\hline $\begin{array}{l}\text { HIV duration }(n=9953) \\
1-2 \text { years }\end{array}$ & 1.00 (ref) & & & & & & & \\
\hline $3-5$ years & $0.99(0.83,1.18)$ & 0.943 & $0.96(0.74,1.25$ & 0.743 & $1.09(1.06,1.13)$ & 0.052 & $1.10(1.08,1.20)$ & 0.081 \\
\hline $6-10$ years & $1.91(1.64,2.31)$ & 0.005 & $1.79(1.43,2.46)$ & 0.014 & $1.12(1.09,1.15)$ & 0.027 & $1.12(1.07,1.27)$ & 0.015 \\
\hline$>10$ years & $1.15(1.76,2.74)$ & 0.034 & $1.83(1.41,3.68)$ & 0.041 & $1.19(1.03,1.38$ & 0.018 & $1.19(1.03,1.71)$ & 0.036 \\
\hline $\begin{array}{l}\text { ART duration }(n=9953) \\
1-2 \text { years }\end{array}$ & 1.00 (ref) & & & & & & & \\
\hline $3-5$ years & $0.99(0.85,1.14)$ & 0.858 & $1.04(0.83,1.31$ & 0.726 & $0.98(0.88,1.10$ & 0.739 & $1.01(0.84,1.20$ & 0.955 \\
\hline $6-10$ years & $1.05(0.91,1.21)$ & 0.5 & $1.16(0.85,1.57$ & 0.345 & $1.04(0.94,1.16$ & 0.42 & $1.10(0.87,1.40$ & 0.419 \\
\hline$>10$ years & $1.02(0.80,1.29)$ & 0.884 & $1.27(0.82,1.96$ & 0.285 & $1.23(1.03,1.47$ & 0.026 & $1.15(0.82,1.61$ & 0.413 \\
\hline $\begin{array}{c}\text { Clinical latency }(n=9953 \\
1-2 \text { years }\end{array}$ & 1.00 (ref) & & & & & & & \\
\hline $3-5$ years & $1.01(0.89,1.14)$ & 0.917 & $1.01(0.86,1.20$ & 0.873 & $1.10(1.00,1.21$ & 0.054 & $1.08(0.95,1.23$ & 0.244 \\
\hline$>5$ years & $0.91(0.74,1.12)$ & 0.354 & $0.97(0.71,1.32$ & 0.846 & $1.09(0.93,1.26$ & 0.294 & $1.00(0.78,1.27$ & 0.993 \\
\hline $\begin{array}{r}\text { Treatment outcomes }(n= \\
\text { Treatment adherent }\end{array}$ & 1.00 (ref) & & & & & & & \\
\hline Defaulters \& LTFU & $1.08(0.95,1.23)$ & 0.243 & $1.07(0.93,1.23$ & 0.323 & $0.93(0.84,1.02$ & 0.128 & $0.99(0.89,1.10$ & 0.812 \\
\hline Died & $1.04(0.88,1.22)$ & 0.632 & $1.07(0.86,1.32$ & 0.556 & $0.98(0.86,1.11$ & 0.702 & $0.92(0.78,1.09$ & 0.354 \\
\hline
\end{tabular}


Table 6: Factors Associated with Manifestation of Protozoal (Parasitic) and Neoplastic Opportunistic Diseases among HIV-infected adults in Malawi; 2004-2015

\begin{tabular}{|c|c|c|c|c|c|c|c|c|}
\hline \multirow{3}{*}{ Characteristics } & \multicolumn{4}{|c|}{ Protozoal Factors } & \multicolumn{4}{|c|}{ Neoplasm Factors } \\
\hline & \multicolumn{2}{|c|}{$\begin{array}{c}\text { Univariable } \\
\text { findings }\end{array}$} & \multicolumn{2}{|c|}{$\begin{array}{c}\text { Multivariable } \\
\text { findings }\end{array}$} & \multicolumn{2}{|c|}{$\begin{array}{c}\text { Univariable } \\
\text { findings }\end{array}$} & \multicolumn{2}{|c|}{$\begin{array}{c}\text { Multivariable } \\
\text { findings }\end{array}$} \\
\hline & OR $(95 \% \mathrm{CI})$ & $\begin{array}{c}\text { p- } \\
\text { value }\end{array}$ & $\operatorname{aOR}(95 \% \mathrm{CI})$ & p-value & OR $(95 \% \mathrm{CI})$ & p-value & aOR $(95 \% \mathrm{CI})$ & p-value \\
\hline $\begin{array}{c}\text { Care type }(n=9953) \\
\text { Primary care }\end{array}$ & 1.00 (ref) & & & & & & & \\
\hline Secondary care & $0.91(0.68,1.22$ & 0.537 & $0.97(0.72,1.32$ & 0.871 & $1.92(1.60,2.40$ & 0.048 & $1.86(1.55,2.35$ & 0.014 \\
\hline Tertiary care & $1.05(0.80,1.36$ & 0.741 & $1.09(0.83,1.43$ & 0.531 & $1.97(1.65,2.43$ & 0.008 & $1.94(1.63,2.42$ & 0.007 \\
\hline $\begin{array}{l}\text { Gender }(n=9953) \\
\text { Female }\end{array}$ & $1.00(\mathrm{ref})$ & & & & & & & \\
\hline Male & $1.07(1.03,1.23$ & 0.043 & $1.05(1.02,1.25$ & 0.046 & $0.72(0.58,0.90$ & 0.003 & $0.73(0.56,0.95$ & 0.021 \\
\hline $\begin{array}{c}\text { Age-group }(n=9950) \\
15-19 \text { years }\end{array}$ & 1.00 (ref) & & & & & & & \\
\hline 20-39 years & $0.69(0.50,0.96$ & 0.026 & $0.65(0.45,0.94$ & 0.024 & $1.77(0.86,3.63$ & 0.118 & $1.20(0.55,2.62$ & 0.641 \\
\hline 40-54 years & $0.71(0.51,0.99$ & 0.041 & $0.68(0.46,0.99$ & 0.046 & $1.73(0.84,3.55$ & 0.137 & $1.20(0.55,2.64$ & 0.644 \\
\hline $55+$ years & $0.58(0.40,0.85$ & 0.005 & $0.56(0.36,0.85$ & 0.007 & $1.71(0.80,3.63$ & 0.167 & $1.35(0.59,3.08$ & 0.476 \\
\hline $\begin{array}{l}\text { Residential area }(n=9953 \\
\quad \text { Rural }\end{array}$ & 1.00 (ref) & & & & & & & \\
\hline Semi-urban & $0.99(0.78,1.25$ & 0.905 & $0.92(0.71,1.18$ & 0.496 & $0.99(0.70,1.42$ & 0.973 & $1.05(0.72,1.53$ & 0.818 \\
\hline Urban & $1.06(0.89,1.27$ & 0.483 & $1.02(0.85,1.22$ & 0.844 & $0.99(0.76,1.28$ & 0.935 & $1.00(0.76,1.31$ & 0.984 \\
\hline $\begin{array}{c}\text { Regional area }(n=9953) \\
\text { Central region }\end{array}$ & $1.00(\mathrm{ref})$ & & & & & & & \\
\hline Northern Region & $1.14(0.92,1.42$ & 0.239 & $1.08(0.86,1.35$ & 0.517 & $0.96(0.69,1.35$ & 0.828 & $1.01(0.70,1.45$ & 0.949 \\
\hline Southern Region & $1.04(0.88,1.23$ & 0.636 & $1.06(0.89,1.26$ & 0.498 & $1.03(0.81,1.32$ & 0.796 & $1.00(0.77,1.29$ & 0.976 \\
\hline $\begin{array}{r}\text { Marital status ( } n=9949) \\
\text { Previously married }\end{array}$ & 1.00 (ref) & & & & & & & \\
\hline $\begin{array}{l}\text { Married } \\
\text { (partnership) }\end{array}$ & $1.13(0.92,1.39$ & 0.25 & $1.11(0.90,1.37$ & 0.338 & $0.96(0.72,1.28$ & 0.77 & $1.01(0.74,1.37$ & 0.962 \\
\hline $\begin{array}{l}\text { Single (never } \\
\text { married) }\end{array}$ & $1.20(0.88,1.64$ & 0.246 & $1.05(0.74,1.49$ & 0.785 & $0.49(0.28,0.88$ & 0.017 & $0.58(0.31,0.89$ & 0.054 \\
\hline $\begin{array}{l}\text { Education level }(n=9953 \\
\text { Primary }\end{array}$ & 1.00 (ref) & & & & & & & \\
\hline Primary & $0.85(0.64,1.13$ & 0.26 & $0.90(0.67,1.21$ & 0.48 & $0.99(0.64,1.53$ & 0.965 & $1.14(0.72,1.82$ & 0.571 \\
\hline Secondary & $0.99(0.75,1.30$ & 0.921 & $1.08(0.80,1.45$ & 0.62 & $1.03(0.67,1.58$ & 0.903 & $1.25(0.78,2.01$ & 0.349 \\
\hline Higher & $1.00(0.75,1.32$ & 0.977 & $0.99(0.73,1.36$ & 0.973 & $1.12(0.72,1.73$ & 0.611 & $1.42(0.87,2.32$ & 0.158 \\
\hline $\begin{array}{l}\text { Employment status ( } n=9 \\
\text { Employed }\end{array}$ & 1.00 (ref) & & & & & & & \\
\hline Self-employed & $0.92(0.80,1.06$ & 0.244 & $0.90(0.78,1.04$ & 0.165 & $0.96(0.78,1.18$ & 0.673 & $1.03(0.82,1.29$ & 0.783 \\
\hline $\begin{array}{l}\text { Occupation type }(n=995 \\
\text { Manual jobs }\end{array}$ & $1.00(\mathrm{ref})$ & & & & & & & \\
\hline Other job types & $1.15(0.94,1.41$ & 0.182 & $1.16(0.93,1.44$ & 0.187 & $1.31(0.96,1.79$ & 0.094 & $1.48(1.05,2.08$ & 0.025 \\
\hline White collar & $1.23(1.02,1.52$ & 0.054 & $1.26(1.05,1.58$ & 0.052 & $1.25(0.90,1.74$ & 0.18 & $1.28(0.89,1.84$ & 0.179 \\
\hline
\end{tabular}




\begin{tabular}{|c|c|c|c|c|c|c|c|c|}
\hline \multicolumn{9}{|c|}{ ART initiation criteria $(n=9953)$} \\
\hline PMTCT & $1.18(0.75,1.85$ & 0.484 & $1.24(0.78,1.96$ & 0.358 & $0.27(0.06,1.09$ & 0.065 & $0.23(0.06,0.96$ & 0.043 \\
\hline WHO III & $1.32(1.11,1.58$ & 0.002 & $1.36(1.13,1.64$ & 0.001 & $0.69(0.50,0.94$ & 0.02 & $0.69(0.49,0.97$ & 0.03 \\
\hline WHO IV & $1.21(0.99,1.49$ & 0.062 & $1.26(1.02,1.56$ & 0.034 & $3.24(2.46,4.27$ & 0.0001 & $3.43(2.53,4.65$ & 0.0001 \\
\hline \multicolumn{9}{|c|}{ CD4-initial results $(n=9944)$} \\
\hline$>250$ cells $/ \mu \mathrm{L}$ & $0.98(0.84,1.14$ & 0.793 & $0.99(0.85,1.16$ & 0.944 & $1.05(0.84,1.32$ & 0.645 & $0.93(0.74,0.97$ & 0.054 \\
\hline \multicolumn{9}{|c|}{ CD4-recent results $(n=9951)$} \\
\hline $501-1000$ cells $/ \mu \mathrm{L}$ & $0.90(0.77,1.04$ & 0.154 & $0.81(0.66,0.99$ & 0.042 & $1.10(0.87,1.39$ & 0.434 & $0.98(0.71,1.34$ & 0.888 \\
\hline$>1000$ cells $/ \mu \mathrm{L}$ & $0.89(0.72,1.10$ & 0.283 & $0.77(0.60,1.00$ & 0.047 & $1.03(0.75,1.42$ & 0.85 & $0.85(0.57,1.26$ & 0.416 \\
\hline \multicolumn{9}{|c|}{ VL-initial results $(n=9945)$} \\
\hline$>1000$ copies $/ \mathrm{mL}$ & $1.39(1.19,2.11$ & 0.012 & $1.15(1.07,1.79$ & 0.042 & $1.11(1.06,1.90$ & 0.023 & $1.74(1.39,2.40$ & 0.036 \\
\hline \multicolumn{9}{|c|}{$\begin{array}{l}\text { VL-recent results }(n=9953) \\
0-40 \text { copies } / \mathrm{mL}\end{array}$} \\
\hline $\begin{array}{l}41-1000 \\
\text { copies } / \mathrm{mL}\end{array}$ & $1.06(0.90,1.25$ & 0.481 & $0.97(0.80,1.16$ & 0.719 & $1.02(0.80,1.30$ & 0.869 & $0.98(0.75,1.28$ & 0.863 \\
\hline \multicolumn{9}{|c|}{ Current ART regimen $(n=9953)$} \\
\hline Efavirenz-based & $0.98(0.83,1.15$ & 0.791 & $1.01(0.86,1.19$ & 0.891 & $1.05(0.82,1.35$ & 0.68 & $1.05(0.81,1.35$ & 0.718 \\
\hline Boosted-Ritonavir & $0.82(0.53,1.26$ & 0.373 & $0.84(0.55,1.30$ & 0.434 & $1.20(0.67,2.13$ & 0.54 & $1.24(0.69,2.24$ & 0.474 \\
\hline Non-std. & $1.81(1.10,2.97$ & 0.02 & $1.78(1.08,2.93$ & 0.024 & $1.52(0.69,3.36$ & 0.297 & $1.59(0.70,3.57$ & 0.265 \\
\hline \multicolumn{9}{|l|}{ HIV duration ( $n=9953)$} \\
\hline $3-5$ years & $1.00(0.80,1.26$ & 0.974 & $0.85(0.59,1.22$ & 0.387 & $1.09(0.78,1.54$ & 0.608 & $0.93(0.55,1.57$ & 0.784 \\
\hline $6-10$ years & $0.98(0.79,1.21$ & 0.836 & $0.72(0.45,1.14$ & 0.16 & $0.96(0.69,1.33$ & 0.803 & $0.79(0.40,1.57$ & 0.508 \\
\hline$>10$ years & $0.91(0.71,1.18$ & 0.496 & $0.56(0.30,1.05$ & 0.071 & $1.05(0.72,1.54$ & 0.799 & $1.00(0.40,2.52$ & 0.996 \\
\hline \multicolumn{9}{|l|}{ ART duration $(n=9953)$} \\
\hline $3-5$ years & $1.07(0.89,1.30$ & 0.473 & $1.23(0.89,1.69$ & 0.203 & $1.06(0.80,1.41$ & 0.682 & $1.12(0.71,1.77$ & 0.616 \\
\hline 6-10 years & $1.08(0.90,1.30$ & 0.422 & $1.42(0.93,2.16$ & 0.103 & $1.02(0.77,1.35$ & 0.89 & $1.23(0.66,2.29$ & 0.511 \\
\hline$>10$ years & $1.07(0.79,1.46$ & 0.662 & $1.71(0.95,3.08$ & 0.076 & $1.05(0.66,1.68$ & 0.83 & $1.14(0.48,2.71$ & 0.772 \\
\hline \multicolumn{9}{|l|}{ Clinical latency $(n=9953)$} \\
\hline $3-5$ years & $0.85(0.72,1.01$ & 0.07 & $1.00(0.79,1.25$ & 0.974 & $1.07(0.84,1.36$ & 0.588 & $1.02(0.73,1.42$ & 0.911 \\
\hline$>5$ years & $0.96(0.74,1.25$ & 0.776 & $1.37(0.91,2.06$ & 0.131 & $0.79(0.51,1.23$ & 0.31 & $0.73(0.38,1.39$ & 0.334 \\
\hline \multicolumn{9}{|c|}{ Treatment outcomes $(n=9953)$} \\
\hline $\begin{array}{l}\text { Treatment } \\
\text { adherent }\end{array}$ & 1.00 (ref) & & & & & & & \\
\hline $\begin{array}{l}\text { Defaulters \& } \\
\text { LTFU }\end{array}$ & $0.94(0.79,1.12$ & 0.476 & $0.95(0.79,1.15$ & 0.613 & $0.92(0.71,1.20$ & 0.544 & $0.77(0.58,1.02$ & 0.069 \\
\hline Died & $0.87(0.69,1.08$ & 0.212 & $0.78(0.59,1.04$ & 0.089 & $0.94(0.68,1.31$ & 0.731 & $1.15(0.74,1.79$ & 0.523 \\
\hline
\end{tabular}


710 AVERT (2019) HIV and AIDS in Malawi:. Available from: https://www.avert.org/professionals/hiv-around711 world/sub-saharan-africa/malawi (Accessed Nov 2018).

712

Benson, C. A., Kaplan, J. E., Masur, H., Pau, A. \& Holmes, K. K. (2004) Treating opportunistic infections among HIV-infected adults and adolescents: recommendations from CDC, the National Institutes of Health, and the HIV Medicine Association/Infectious Diseases Society of America. MMWR. Recommendations and reports : Morbidity and mortality weekly report. Recommendations and reports, 53 (RR-15): 1-112.

Bonnet, F., Lewden, C., May, T., Heripret, L., Jougla, E., Bevilacqua, S., Costagliola, D., Salmon, D., Chene, G. \& Morlat, P. (2005) Opportunistic infections as causes of death in HIV-infected patients in the HAART era in France. Scandinavian journal of infectious diseases, 37 (6-7): 482-487.

Brooks, J. T., Kaplan, J. E., Holmes, K. K., Benson, C., Pau, A. \& Masur, H. (2009) HIV-associated opportunistic infections--going, going, but not gone: the continued need for prevention and treatment guidelines. Clinical infectious diseases : an official publication of the Infectious Diseases Society of America, 48 (5): 609 611.

Caruz, A., Samsom, M., Alonso, J. M., Alcami, J., Baleux, F., Virelizier, J. L., Parmentier, M. \& ArenzanaSeisdedos, F. (1998) Genomic organization and promoter characterization of human CXCR4 gene. FEBS letters, 426 (2): 271-278.

Chaisson, R. E. \& Moore, R. D. (1997) Prevention of opportunistic infections in the era of improved antiretroviral therapy. Journal of acquired immune deficiency syndromes and human retrovirology : official publication of the International Retrovirology Association, 16 Suppl 1 S14-22.

Charan, J. \& Biswas, T. (2013) How to Calculate Sample Size for Different Study Designs in Medical Research? Indian J Psychol Med, 35 (2): 121-126.

Chirwa, Z., Kayambo, F., Oseni, L., Plotkin, M., Hiner, C., Chitsulo, C., Curran, K., Kalua, T. \& Stender, S. C. (2018) Extending beyond Policy: Reaching UNAIDS' Three "90"s in Malawi. Front Public Health, 669.

Colebunders, R. L. \& Latif, A. S. (1991) Natural history and clinical presentation of HIV-1 infection in adults. AIDS (London, England), 5 Suppl 1 S103-112.

Corey, D. M., Kim, H. W., Salazar, R., Illescas, R., Villena, J., Gutierrez, L., Sanchez, J. \& Tabet, S. R. (2007) Brief report: effectiveness of combination antiretroviral therapy on survival and opportunistic infections in a developing world setting: an observational cohort study. Journal of acquired immune deficiency syndromes (1999), 44 (4): 451-455.

Croxford, S., Kitching, A., Desai, S., Kall, M., Edelstein, M., Skingsley, A., Burns, F., Copas, A., Brown, A. E., Sullivan, A. K. \& Delpech, V. (2017) Mortality and causes of death in people diagnosed with HIV in the era of highly active antiretroviral therapy compared with the general population: an analysis of a national observational cohort. Lancet Public Health, 2 (1): e35-e46.

Damtie, D., Yismaw, G., Woldeyohannes, D. \& Anagaw, B. (2013) Common opportunistic infections and their CD4 cell correlates among HIV-infected patients attending at antiretroviral therapy clinic of Gondar University Hospital, Northwest Ethiopia. BMC research notes, 6 534-534.

Daniel, W. W. (1999) Biostatistics : a foundation for analysis in the health sciences. 7th edn. New York: John Wiley \& Sons. 
Daniel, W. W. \& Cross, C. L. (2013) Biostatistics : a foundation for analysis in the health sciences. 10th edn. Hoboken, NJ: Wiley.

FMOH. (2008) Federal HIV/AIDS Prevention and Control Office, Federal Ministry of Health Guidelines for Management of Opportunistic Infections and Anti-Retroviral Treatment in Adolescents and Adults in Ethiopia. 2008. Available from: http://www.who.int/hiv/pub/guidelines/ethiopia_art.pdf(Accessed October 2018).

Geubbels, E. \& Bowie, C. (2006) Epidemiology of HIV/AIDS in adults in Malawi. Malawi medical journal : the journal of Medical Association of Malawi, 18 (3): 111-133.

Ghys, P. D., Zaba, B. \& Prins, M. (2007) Survival and mortality of people infected with HIV in low and middle income countries: results from the extended ALPHA network. AIDS, 21 Suppl 6 S1-4.

Gorstein, J., Sullivan, K. M., Parvanta, I. \& Begin, F. (2007) Indicators and Methods for Cross-Sectional

Surveys of Vitamin and Mineral Status of Populations. The Micronutrient Initiative (Ottawa) and the Centers for Disease Control and Prevention (Atlanta).

Hajian-Tilaki, K. (2011) Sample size estimation in epidemiologic studies. Caspian J Intern Med, 2 (4): 289-298.

Hargreaves, N. J., Kadzakumanja, O., Phiri, S., Lee, C. H., Tang, X., Salaniponi, F. M., Harries, A. D. \& Squire, S. B. (2001) Pneumocystis carinii pneumonia in patients being registered for smear-negative pulmonary tuberculosis in Malawi. Transactions of the Royal Society of Tropical Medicine and Hygiene, 95 (4): 402-408.

Harries, A. D., Nyangulu, D. S., Kang'ombe, C., Ndalama, D., Glynn, J. R., Banda, H., Wirima, J. J., Salaniponi, F. M., Liomba, G., Maher, D. \& Nunn, P. (1998) Treatment outcome of an unselected cohort of tuberculosis patients in relation to human immunodeficiency virus serostatus in Zomba Hospital, Malawi. Trans $R$ Soc Trop Med Hyg, 92 (3): 343-347.

Hogg, R. S., Yip, B., Kully, C., Craib, K. J., O'Shaughnessy, M. V., Schechter, M. T. \& Montaner, J. S. (1999) Improved survival among HIV-infected patients after initiation of triple-drug antiretroviral regimens. CMAJ : Canadian Medical Association journal = journal de l'Association medicale canadienne, 160 (5): 659-665.

Holmes, C. B., Losina, E., Walensky, R. P., Yazdanpanah, Y. \& Freedberg, K. A. (2003) Review of Human Immunodeficiency Virus Type 1-Related Opportunistic Infections in Sub-Saharan Africa.

Iroezindu, M. O. (2013) Prevalence and Risk Factors for Opportunistic Infections in HIV Patients Receiving

Iroezindu, M. O. (2016) Disparities in the Magnitude of Human Immunodeficiency Virus-related Opportunistic the Trend? Annals of medical and health sciences research, 6 (1): 4-18.

Jahn, A., Harries, A. D., Schouten, E. J., Libamba, E., Ford, N., Maher, D. \& Chimbwandira, F. (2016) Scaling- 

(2016) Scale-up of ART in Malawi has reduced case notification rates in HIV-positive and HIV-negative tuberculosis. Public health action, 6 (4): 247-251.

812

813

814
Kanyerere, H., Mganga, A., Harries, A. D., Tayler-Smith, K., Jahn, A., Chimbwandira, F. M. \& Mpunga, J. (2014) Decline in national tuberculosis notifications with national scale-up of antiretroviral therapy in Malawi. (2220-8372 (Print)):

Knauer, A., Das, A. K., Tansuphasawadikul, S., Supanaranond, W., Pitisuttithum, P. \& Wernsdorfer, W. H. (2005) Clinical features, aetiology and short-term outcome of interstitial pneumonitis in HIV/AIDS patients at Bamrasnaradura Hospital, Nonthaburi, Thailand. Wien Klin Wochenschr, 117 Suppl 4 49-55.

Kumwenda, N. I., Taha, T. E., Hoover, D. R., Markakis, D., Liomba, G. N., Chiphangwi, J. D. \& Celentano, D. D. (2001) HIV-1 incidence among male workers at a sugar estate in rural Malawi. Journal of acquired immune deficiency syndromes (1999), 27 (2): 202-208.

Kwanjana, J. H., Harries, A. D., Gausi, F., Nyangulu, D. S. \& Salaniponi, F. M. (2001) TB-HIV seroprevalence in patients with tuberculosis in Malawi.

Lifson, A. R., Rutherford, G. W. \& Jaffe, H. W. (1988) The natural history of human immunodeficiency virus infection. The Journal of infectious diseases, 158 (6): 1360-1367.

Mageda, K., Leyna, G. H. \& Mmbaga, E. J. (2012) High Initial HIV/AIDS-Related Mortality and -Its Predictors among Patients on Antiretroviral Therapy in the Kagera Region of Tanzania: A Five-Year Retrospective Cohort Study. AIDS Res Treat, 2012843598.

Malawi-MoH (2017) Malawi Population-based HIV Impact Assessment (MPHIA) 2015-16: First Report. [online] Lilongwe: Ministry of Health. November 2017. Available from: https://phia.icap.columbia.edu/wpcontent/uploads/2017/11/Final-MPHIA-First-Report 11.15.17.pdf (Accessed Dec 2018).

Manosuthi, W., Chaovavanich, A., Tansuphaswadikul, S., Prasithsirikul, W., Inthong, Y., Chottanapund, S., Sittibusaya, C., Moolasart, V., Termvises, P. \& Sungkanuparph, S. (2007) Incidence and risk factors of major opportunistic infections after initiation of antiretroviral therapy among advanced HIV-infected patients in a resource-limited setting. J Infect, 55 (5): 464-469.

MDHS. (2010) National Statistical Office - NSO/Malawi and ICF Macro. 2011. Malawi Demographic and Health Survey 2010. Zomba, Malawi: NSO/Malawi and ICF Macro. (May, 2015): Available from: https://dhsprogram.com/publications/publication-fr247-dhs-final-reports.cfm(Accessed May, 2015).

Miller, V., Mocroft, A., Reiss, P., Katlama, C., Papadopoulos, A. I., Katzenstein, T., van Lunzen, J., Antunes, F., Phillips, A. N. \& Lundgren, J. D. (1999) Relations among CD4 lymphocyte count nadir, antiretroviral therapy, and HIV-1 disease progression: results from the EuroSIDA study. Annals of internal medicine, 130 (7): 570-577.

Mitiku, H., Weldegebreal, F. \& Teklemariam, Z. (2015) Magnitude of opportunistic infections and associated factors in HIV-infected adults on antiretroviral therapy in eastern Ethiopia. HIV AIDS (Auckl), 7 137-144.

Moges, N. A. \& Kassa, G. M. (2014) Prevalence of Opportunistic Infections and Associated Factors among HIV Positive Patients taking Anti-Retroviral Therapy in DebreMarkos Referral Hospital, Northwest Ethiopia. Journal of AIDS \& Clinical Research, 05 (05): 
MOH (2011) Clinical management of HIV in Children and Adults: Malawi integrated guidelines and standard operating procedure for providing HIV services, $1^{\text {st }}$ ed. [online] Available from:

862 http://apps.who.int/medicinedocs/en/d/Js18802en/ (Accessed March 2018).

863

864

865

866

867

868

869

870

871

872

873

874

875

876

877

878

879

880

881

882

883

884

885

886

887

888

889

890

891

892

893

894

895

896

897

898

899

900

901

902

903

904

905

906

907

908

MOH. (2017) Health Sector Strategic Plan II 2017-2022; Towards Universal Health Coverage. Available from: www.health.gov.mw/index.php/policies-strategies?download=47:hssp-ii-final(Accessed December 2017).

Mzileni, M. O., Longo-Mbenza, B. \& Chephe, T. J. (2008) Mortality and causes of death in HIV-positive patients receiving antiretroviral therapy at Tshepang Clinic in Doctor George Mukhari Hospital. Polskie Archiwum Medycyny Wewnetrznej, 118 (10): 548-554.

NAC (2003) Estimating National HIV Prevalence in Malawi from Sentinel Surveillance Data. Available from: http://www.policyproject.com/pubs/countryreports/MalSS.pdf (Accessed Aug 2017).

NAC/MOH \& UNAIDS (2015) Malawi AIDS Response Progress Report 2015. Available from: https://www.unaids.org/sites/default/files/country/documents/MWI_narrative_report 2015.pdf (Accessed Dec. 2017). Lilongwe: NAC/MOH.

Naing, L., Winn, T. \& Rusli, B. N. (2006) Practical Issues in Calculating the Sample Size for Prevalence Studies. Archives of Orofacial Sciences, 19-14.

Paton, N. I., Sangeetha, S., Earnest, A. \& Bellamy, R. (2006) The impact of malnutrition on survival and the CD4 count response in HIV-infected patients starting antiretroviral therapy. HIV medicine, 7 (5): 323-330.

Pilcher, C. D., Price, M. A., Hoffman, I. F., Galvin, S., Martinson, F. E. A., Kazembe, P. N., Eron, J. J., Miller, W. C., Fiscus, S. A. \& Cohen, M. S. (2004) Frequent detection of acute primary HIV infection in men in Malawi. AIDS (London, England), 18 (3): 517-524.

Reniers, G., Slaymaker, E., Nakiyingi-Miiro, J., Nyamukapa, C., Crampin, A. C., Herbst, K., Urassa, M., Otieno, F., Gregson, S., Sewe, M., Michael, D., Lutalo, T., Hosegood, V., Kasamba, I., Price, A., Nabukalu, D., McLean, E. \& Zaba, B. (2014) Mortality trends in the era of antiretroviral therapy: evidence from the Network for Analysing Longitudinal Population based HIV/AIDS data on Africa (ALPHA). Aids, 28 Suppl 4 (4): S533542.

Rubaihayo, J., Tumwesigye, N. \& Konde-Lule, J. (2015) Trends in prevalence of selected opportunistic infections associated with HIV/AIDS in Uganda. BMC infectious diseases, 15 (1):

Rubaihayo, J., Tumwesigye, N. M., Konde-Lule, J., Wamani, H., Nakku-Joloba, E. \& Makumbi, F. (2016) Frequency and distribution patterns of opportunistic infections associated with HIV/AIDS in Uganda. $B M C$ Research Notes, 9501.

Selik, R. M., Starcher, E. T. \& Curran, J. W. (1987) Opportunistic diseases reported in AIDS patients: frequencies, associations, and trends. AIDS (London, England), 1 (3): 175-182.

Siberry, G. K., Abzug, M. J. \& Nachman, S. (2013) Executive Summary: Guidelines for the Prevention and Treatment of Opportunistic Infections in HIV-Exposed and HIV-Infected Children: Recommendations From the National Institutes of Health, the Centers for Disease Control and Prevention, the HIV Medicine Association of the Infectious Diseases Society of America, the Pediatric Infectious Diseases Society, and the American Academy of Pediatrics. Journal of the Pediatric Infectious Diseases Society, 2 (4): 293-308. 
910 Simmons, R. D., Ciancio, B. C., Kall, M. M., Rice, B. D. \& Delpech, V. C. (2013) Ten-year mortality trends 911 among persons diagnosed with HIV infection in England and Wales in the era of antiretroviral therapy: AIDS 912 remains a silent killer. HIV medicine, 14 (10): 596-604.

913

914

915

916

917

918

919

920

921

922

923

924

925

926

927

928

929

930

931

932

933

934

935

936

937

938

939

940

941

942

943

944

945

946

947

948

949

950

951

952

953

954

955

956

957

958

959

Staine, J. G. (2007) AIDS update 2007: An overview of acquired immune deficiency syndrome. New York:: McGraw-Hill co., Inc; 2008.

Sun, H.-Y., Chen, M.-Y., Hsieh, S.-M., Sheng, W.-H., Chang, S.-Y., Hsiao, C.-F., Hung, C.-C. \& Chang, S.-C. (2006) Changes in the clinical spectrum of opportunistic illnesses in persons with HIV infection in Taiwan in the era of highly active antiretroviral therapy. Japanese journal of infectious diseases, 59 (5): 311-316.

Theuring, S., Mugenyi, K., Rubaihayo, J., Busingye, P. \& Harms, G. (2015) Antiretroviral Therapy Programme Retention and Outcomes after 12 Months in a Retrospective Patient Cohort in Fort Portal, Uganda: The Ongoing Challenge of Male ART Performance.

Trochim, W. M. (2000) The Research Methods Knowledge Base. 2nd edn. Cincinnati, OH.: Atomic Dog Publishing.

Trochim, W. M. (2007) The Research Methods Knowledge Base. [online] Available from:

https://www.researchgate.net/publication/243783609_The_Research_Methods_Knowledge_Base/link/55db8370 08aed6a199ac6246/download (Accessed Dec, 2015).

UNAIDS. (2016) Global AIDS update 2016. Available from: https://www.who.int/hiv/pub/arv/global-AIDSupdate-2016 en.pdf(Accessed September 2018).

UNAIDS (2017a) Global HIV \& AIDS statistics - 2017 fact sheet. Available from:

https://www.unaids.org/en/resources/fact-sheet (Accessed July, 2018). Geneva -online:

UNAIDS (2017b) HIV and AIDS in Malawi-2017. [online] Available from:

https://www.avert.org/professionals/hiv-around-world/sub-saharan-africa/malawi (Accessed December 2018).

UNAIDS (2019a) Global HIV \& AIDS statistics - 2019 fact sheet. Available from:

https://www.unaids.org/en/resources/fact-sheet (Accessed Dec, 2019).

UNAIDS (2019b) HIV and AIDS Estimates: Country Factsheets: Malawi. Available from: https://www.unaids.org/en/regionscountries/countries/malawi (Accessed Dec 2018).

UNAIDS \& MOH (2015) Malawi AIDS Response Progress Report 2015. Available from: https://www.unaids.org/sites/default/files/country/documents/MWI_narrative_report_2015.pdf (Accessed Sep 2017).

van Oosterhout, J. J., Laufer, M. K., Graham, S. M., Thumba, F., Perez, M. A., Chimbiya, N., Wilson, L., Chagomerana, M., Molyneux, M. E., Zijlstra, E. E., Taylor, T. E. \& Plowe, C. V. (2005) A community-based study of the incidence of trimethoprim-sulfamethoxazole-preventable infections in Malawian adults living with HIV. J Acquir Immune Defic Syndr, 39 (5): 626-631.

Warndorff, D. K., Yates, M., Ngwira, B., Chagaluka, S., Jenkins, P. A., Drobniewski, F., Ponnighaus, J. M., Glynn, J. R. \& Fine, P. E. (2000) Trends in antituberculosis drug resistance in Karonga District, Malawi, 19861998. The international journal of tuberculosis and lung disease : the official journal of the International Union against Tuberculosis and Lung Disease, 4 (8): 752-757. 

study, Ethiopia. BMC public health, 18 (1): 820-820.

WHO (2005) Summary Country Profile For HIVIAIDS Treatment Scale-Up: Malawi. _. . Available from: www.who.int/hiv/HIVCP_MWI.pdf (Accessed 10 Jan 2017).

WHO (2006) HIV/AIDS Programme Antiretroviral Drugs for Treating Pregnant Women and Preventing HIV

Version. Available from: https://www.who.int/hiv/pub/mtct/en/arvdrugsguidelines.pdf (Accessed Oct, 2016).

WHO. (2007) WHO case definitions of HIV for surveillance and revised clinical staging and immunological classification of HIV-related disease in adults and children. Available from: https://www.who.int/hiv/pub/guidelines/HIVstaging150307.pdf?ua=1ISBN: 9789241595629 (Accessed June 2015).

WHO (2010a) Basic Country Data: Visceral Leishmaniasis in Malawi. Available from: https://www.who.int/leishmaniasis/resources/MALAWI.pdf (Accessed September, 2018). WHO.

979

980

981

982

983

984

985

986

987

988

989

990

991

992

993

994

995

996

997

998

999
WHO. (2010b) WHO | New guidance on prevention of mother-to-child transmission of HIV and infant feeding in the context of HIV. WHO Available from:

http://www.who.int/hiv/pub/mtct/PMTCTfactsheet/en//entity/hiv/pub/mtct/PMTCTfactsheet/en/index.html

(Accessed 2011-02-03 19:12:00).

WHO (2010c) WHO Clinical Staging of HIV for Infants and Children with Established HIV Infection. Available from: http://www.ncbi.nlm.nih.gov/pubmed// (Accessed February, 2016).

WHO (2013) Consolidated guidelines on the use of antiretroviral drugs for treating and preventing HIV infection. Available from: http://www.who.int/hiv/pub/guidelines/arv2013/download/en/ (Accessed Feb 2016).

WHO \& UNAIDS (2016) Global AIDS Update 2016: Malawi. Available from:

https://www.unaids.org/en/regionscountries/countries/malawi (Accessed Jan 2017).

Zachariah, R., Spielmann, M. P., Harries, A. D., Gomani, P., Graham, S. M., Bakali, E. \& Humblet, P. (2003) Passive versus active tuberculosis case finding and isoniazid preventive therapy among household contacts in a rural district of Malawi. The international journal of tuberculosis and lung disease : the official journal of the International Union against Tuberculosis and Lung Disease, 7 (11): 1033-1039. 
Figures

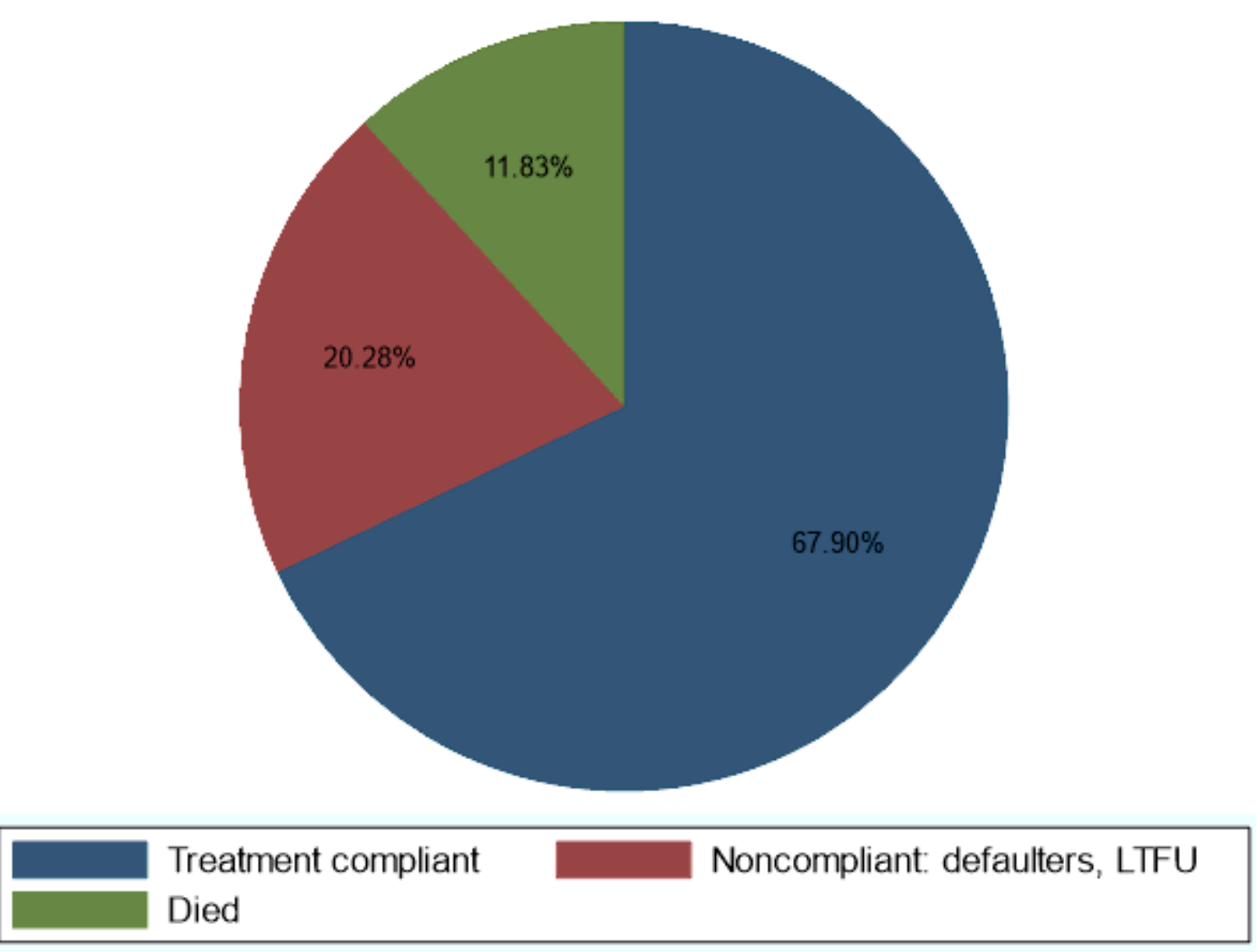

Treatment outcomes in cART-experienced adult patients in Malawi; 2004-2015

\section{Figure 1}

Treatment Outcomes of cART-exposed adults in Malawi; 2004-2015 

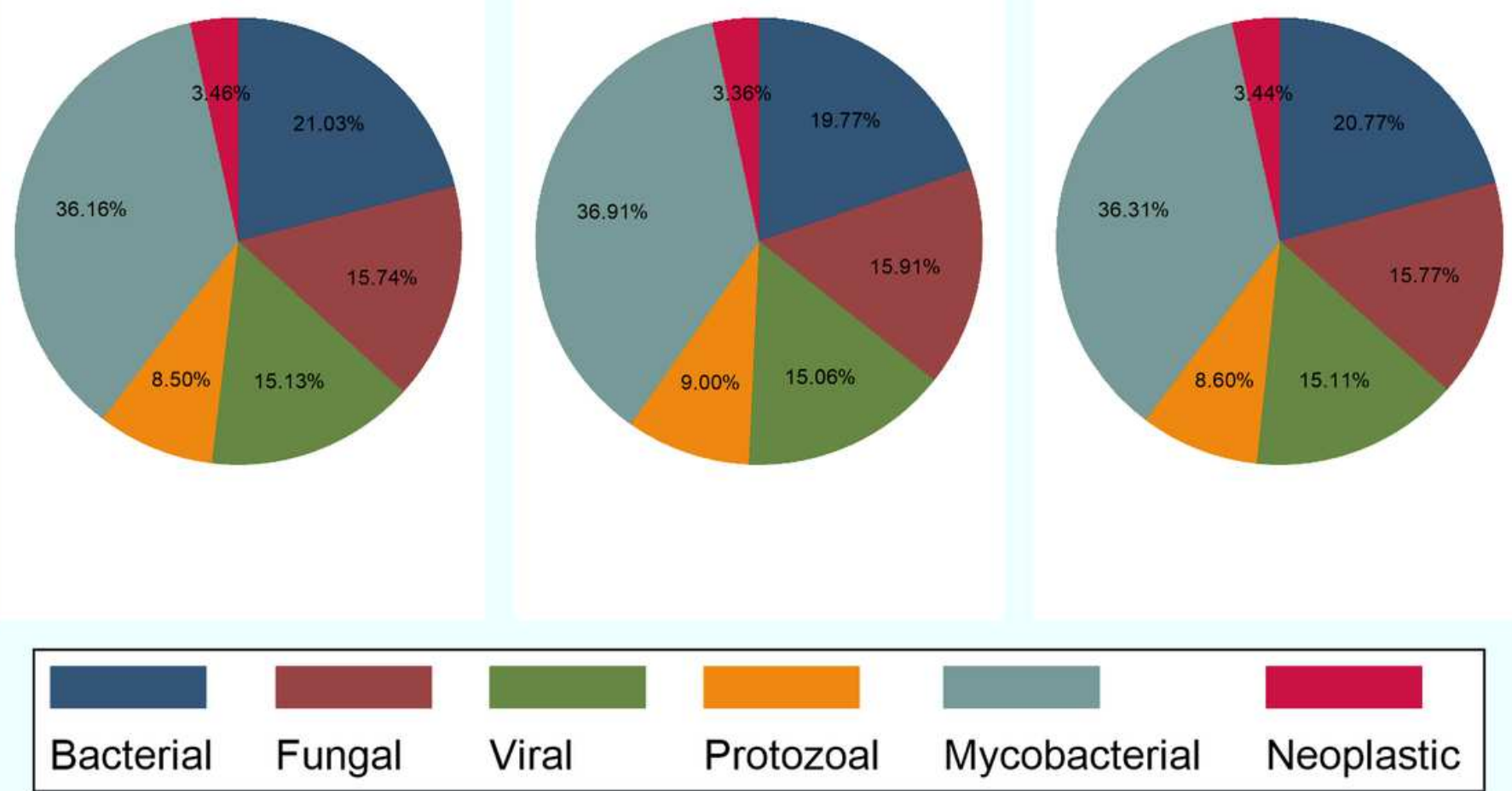

Graphs by ART period

Distribution of AIDS Conditions Aetiological Factors in Malawi; 2004-2015

Figure 2

Distribution of AIDS Conditions Aetiological Factors; Total and by ART Periods in Malawi; 2004-2015 


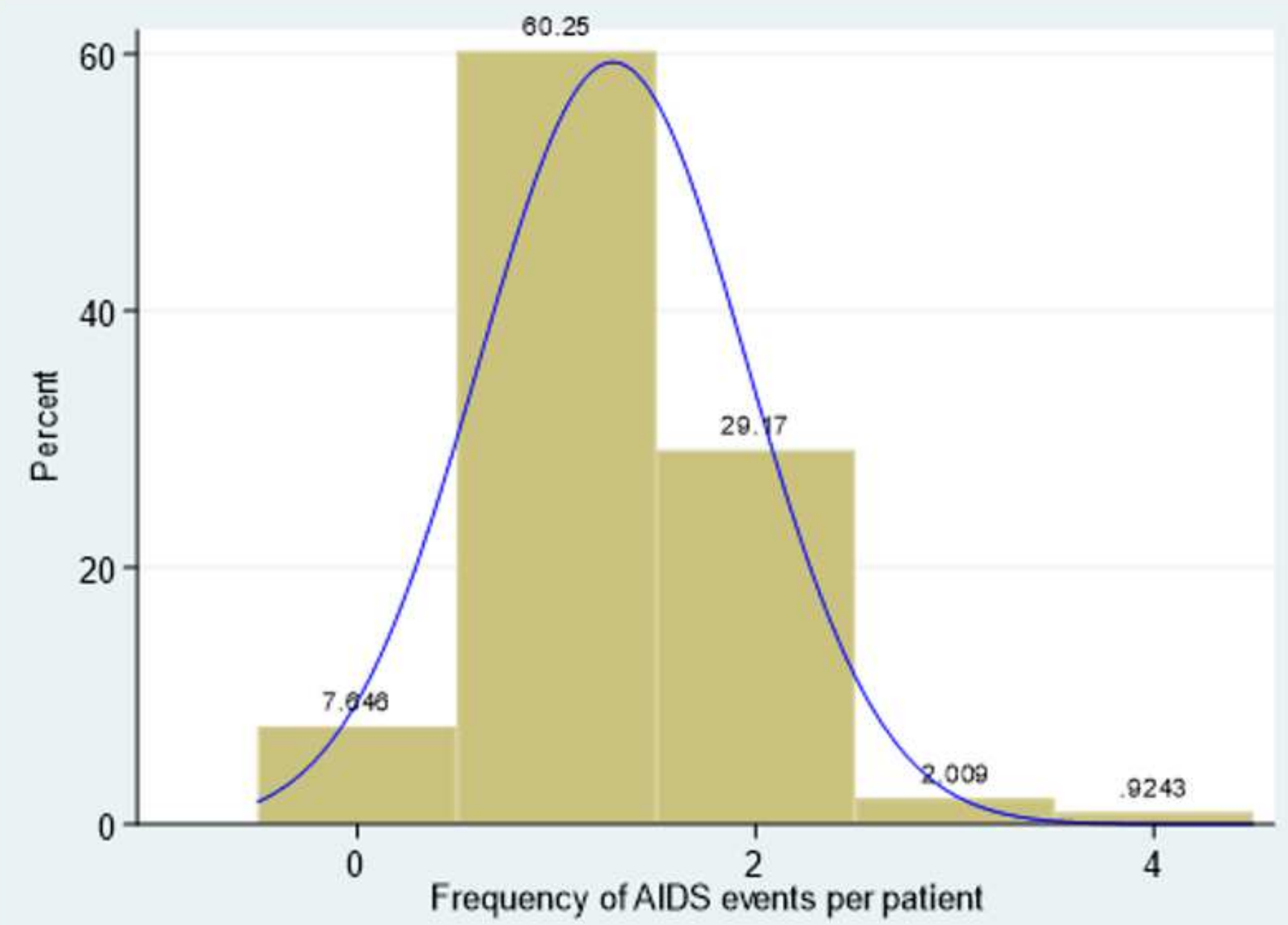

Figure 3

Frequency of AIDS opportunistic events per patient 


\section{HIV vs ART cases by enrolment year}

$\longrightarrow$ HIV cases $\longrightarrow$ ART cases

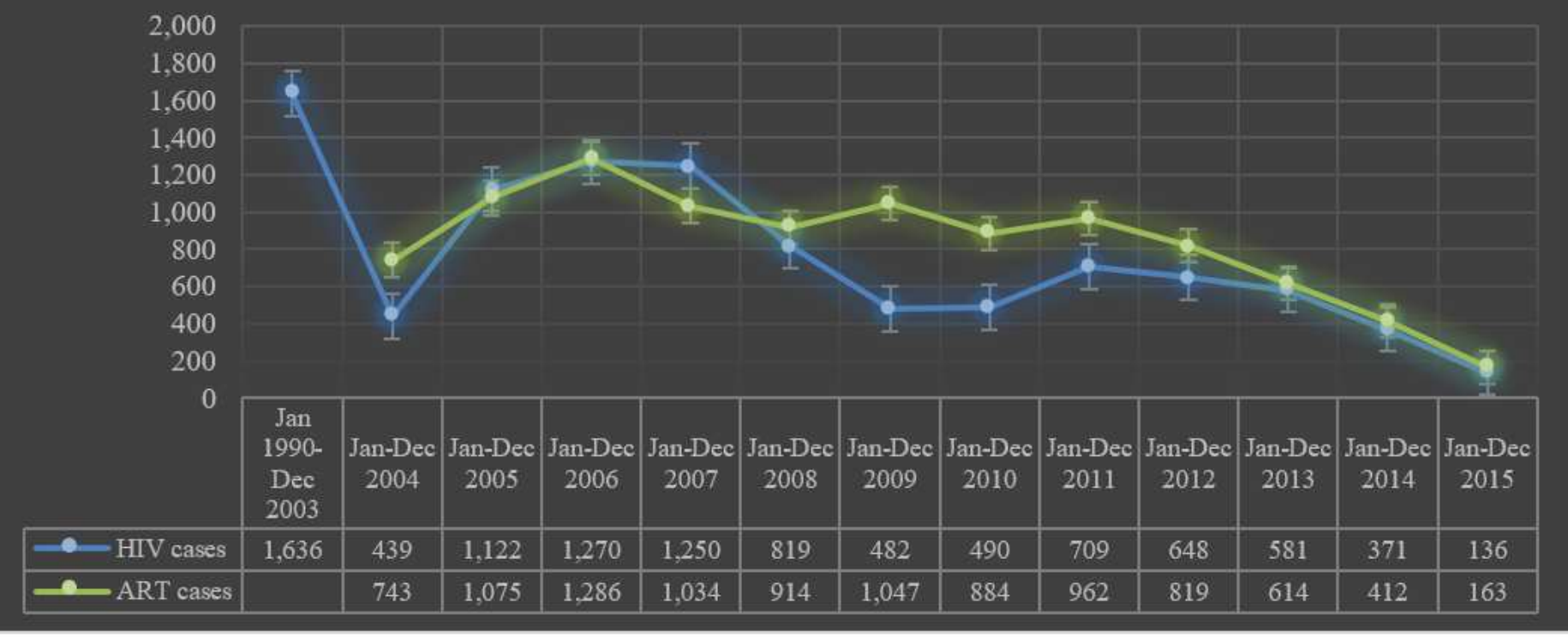

Figure 4

Frequency of HIV diagnosis cases and ODs by enrolment year; 2004-2015 